\title{
Importance of Molybdenum and it Diverse Role in Plant Physiology: A Review
}

\author{
${ }^{1}$ Abou Seeda M. A., ${ }^{1}$ Yassen A. A., ${ }^{2}$ Abou El-Nour E. A. A. and ${ }^{1}$ Sahar M. Zaghloul \\ ${ }^{1}$ Plant Nutrition Dept., National Research Centre, 33 El Buhouth St., 12622 Dokki, Giza, Egypt. \\ ${ }^{2}$ Fertilization Tech. Dept., National Research Centre, 33 El Buhouth St., 12622 Dokki, Giza, Egypt.
} Received: 20 Jan. 2020 / Accepted 10 April 2020 / Publication date: 30 April. 2020

\begin{abstract}
Nitrogen fertilization is an indispensable part particularly, in modern agricultural practices and rank first among the external inputs to maximize output in agriculture production. Nitrogen fertilizer may contribute substantially to environmental pollution. The continued and unabated use of $\mathrm{N}$ fertilizers would accelerate the depletion of stocks of non-renewable energy resources used in fertilizer production. Nitrogen fertilizers must be sought, thus, emphasis should be laid in developing new production methods that are sustainable both ergonomically and economically practices. When plants are grown under molybdenum deficiency, a number of varied phenotypes develop that hinder plant growth. Most of these phenotypes are associated with reduced activity of molybdoenzymes. These enzymes include the primary nitrogen assimilation enzymes such as Nitrate reductase (NR), and the nitrogen-fixing enzyme nitrogenase found in bacteroids of legume nodules. Biological nitrogen fixation (BNF) can act as a renewable and environmentally sustainable source of $\mathrm{N}$ and can complement or replace fertilizer inputs. Molybdenum (Mo) may alleviate drought stress through enhancing antioxidant defense in plants; drought stress is a major environmental stress that limits plant growth and crop production. Plants have developed various complicated adaptive mechanisms to cope under drought stress by triggering a series of physiological and biochemical. Such mechanisms, antioxidant defense play crucial role in the alleviation of damage caused by drought stress. Phytohormones and signal molecules are involved in the regulation of antioxidant defense, which destroy reactive oxygen species (ROS), and thus, confers drought tolerance to plants. Molybdenum (Mo) extensively reported to facilitate the improvement of abiotic stress tolerance against salinity, and water stress in plants
\end{abstract}

Keywords: Molybdenum natural source, antioxidant defense, nitrate reductase, nitric oxide, drought stress

\section{Introduction}

The natural source of molybdenum (Mo) in soil is igneous and sedimentary rock that forms the parent material, located just below soil horizon C. Through chemical and physical weathering, Mo follows one of two pathways: (1) the minerals within the parent material are broken down and Mo remains in the soil column and deposited in horizons $\mathrm{O}, \mathrm{A}, \mathrm{B}, \mathrm{C}$ or Mo translocated to other regions as alluvial, loess, or glacial deposits Smith et al., (1997). The three-main natural mineral deposit of raw materials that naturally contain Mo in soil are molybdenite, wulfenite, and ferrimolybdenite. Through chemical weathering, these minerals break down, releasing soluble molybdate $\left(\mathrm{MoO}^{-4}\right)$ for immediate plant uptake Kaiser et al., (2005).

Like most nutrients, the availability of Mo for plant uptake is highly dependent upon plant growing environment. The environmental factors that affect Mo root absorption are: soil $\mathrm{pH}$, soil organic matter content, soil texture, water drainage, and concentration of other nutrients (mainly oxides such as iron, aluminum, manganese), present in the soil Haque, (1987); Kaiser et al., (2005); Brady et al., (2008). These environmental factors interact and overlap, and as the chemistry of the soil changes, Mo adsorbs onto cations in the soil during electro-chemical interactions with metals, salts, clay, dissolved organic compounds, and carbohydrates Kaiser et al., (2005).

Corresponding Author: Abou Seeda M.A., Plant Nutrition Dept., National Research Centre, 33 El Buhouth St., 12622 Dokki, Giza, Egypt. E-mail: mabouseeda@gmail.com 

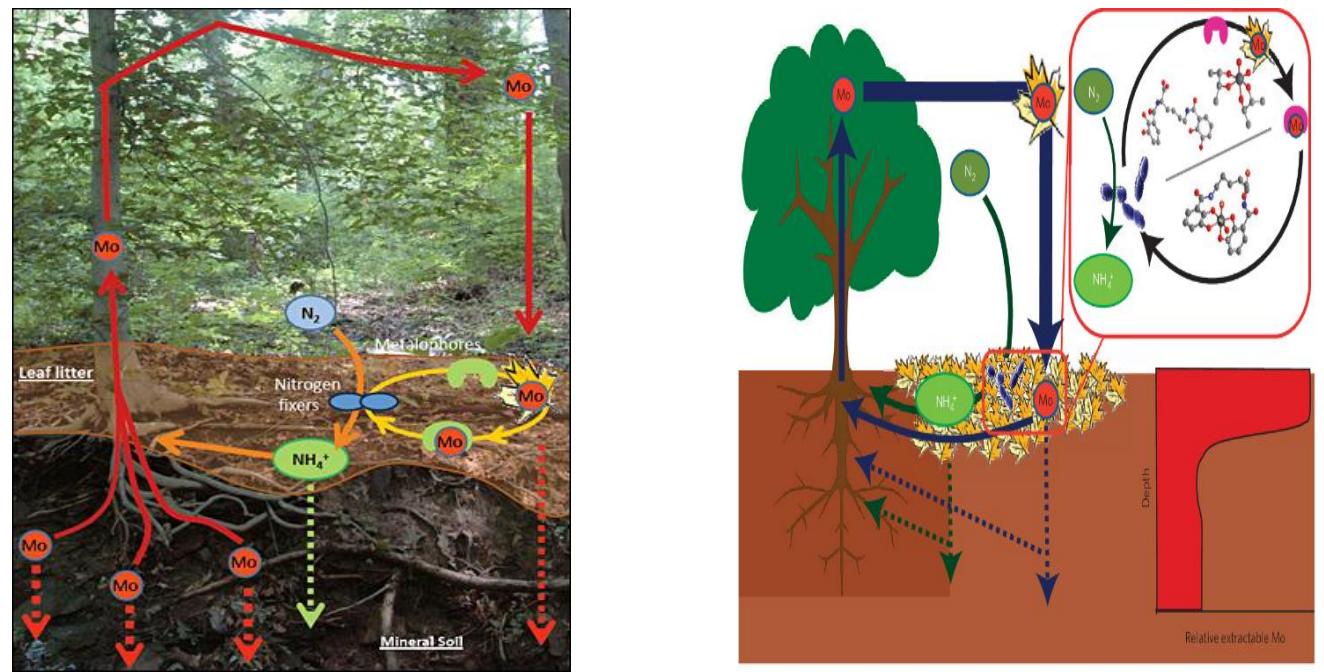

Fig. 1: Illustrate molybdenum cycle in soil, Mo present in deep soil is extracted by the root network of trees and incorporated into leaves. These leaves fall to the ground and decompose, providing a Mo-enriched environment for nitrogen $\mathrm{N}_{2}$-fixing bacteria living in the upper soil. Binding of Mo to leaf organic matter reduces Mo leaching rates from the soil, keeping Mo in the soil environment where it can be used by the bacteria. In turn, the new nitrogen fixed by the bacteria fertilizes tree growth, resulting in a classic mutualistic relationship.

\section{Availability of Molybdenum in Soil}

Molybdenum is a very rare element with a crustal abundance of about $1.2 \mathrm{mg} / \mathrm{kg}$ Fortescue, (1992). Its oxidation state in soils varies from II to VI. Whereas Mo is predicted to be in the IV oxidation state under anoxic conditions Brookings, (1987), Mo is found in oxic soils with a pH of 4-8, mainly as $\mathrm{Mo}^{(\mathrm{Vl})}$ anions and salts $\left(\mathrm{MgMoO}_{4}, \mathrm{CaMoO}_{4}, \mathrm{MoO}_{2}\right.$, Reddy and Gloss, (1993). In more acidic soils (pH <4) protonated $\mathrm{Mo}^{(\mathrm{Vl})}$ compounds $\left(\mathrm{HMoO}_{4}, \mathrm{Mo}(\mathrm{OH})_{6}, \mathrm{HMo}_{2} \mathrm{O}_{7}\right.$ and $\left.\mathrm{H}_{2} \mathrm{MoO}_{4}\right)$ occur. Molybdenum can be dissociated in water, adsorbed by soil colloids, held in crystal lattices of minerals, or bound in organic matter. Total Mo concentrations of about $0.8-3.3 \mathrm{mg} / \mathrm{kg}$ soil were found in a wide range of different soils Kubota, (1977). Only the soluble $\mathrm{Mo}^{(\mathrm{Vl})}$ forms are available for plants. Adsorption on soil particles increases with decreasing pH from 7.75 to 4.45 Reisenauer et al., (1962).Therefore, more Mo is available for plants at higher soil $\mathrm{pH}$ values. Large amounts of $\mathrm{Al}$ and $\mathrm{Fe}$ oxides enhance soil adsorption and reduce the amount of water-soluble Mo Karimian and Cox, (1978).Molybdenum Like other essential nutrients for plant growth and development, Mo availability is pH-dependent Fig (2)

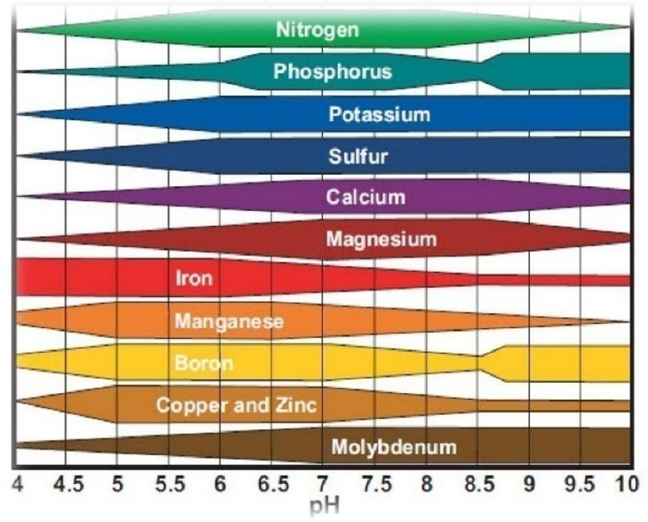

Fig. 2: Illustrate mobility of Molybdenum is $\mathrm{pH}$ dependent

In fact, for every unit increase in soil $\mathrm{pH}$, Mo availability within the soil increases one-hundredfold Gupta, (1997). Molybdenum is classified as a micronutrient; however, the inverse relationship between Mo availability and soil $\mathrm{pH}$ is opposite to most other micronutrients. Alkaline soil $\mathrm{pH}$ allows 
Mo to adsorb readily to cations such as calcium, sodium, potassium, and magnesium. This process increases the available Mo concentrations for immediate plant uptake and Mo losses through leaching Kaiser et al, (2005). Under acidic soil conditions, the opposite occurs. Molybdenum forms a chemical bond with silicates; iron oxide, aluminum oxide, and manganese oxidize to help Mo remain in the soil profile. These complexes prevent root uptake and increase Mo deficiencies in higher-level plants Kaiser et al, (2005); International Plant Nutrition Institute, (2017). Molybdenum and other soil environmental factors soil moisture also affects Mo availability within the soil profile. Heavy textured soils and soils high in organic matter drain slowly Kaiser et al., (2005). When these factors are present, Mo accumulates in the soil and binds with the clay while organic matter slowly decomposes Kaiser et al., (2005). Molybdenum also binds with iron and other oxides within the organic matter and clay, thus, reducing the availability of Mo for root uptake. Once the soil organic matter breaks down in the soil profile, Mo can mineralize and become available for plant uptake Haque, (1987).

In alkaline soils, molybdenum becomes more soluble and is accessible to plants mainly in its anion form as $\mathrm{MoO}^{-4}$.In contrast, in acidic soils $(\mathrm{pH}<5.5)$ molybdenum availability decreases as anion adsorption to soil oxides increase Reddy etal (1997) Fig. (2). When plants are grown under molybdenum deficiency, a number of varied phenotypes develop that hinder plant growth. Most of these phenotypes are associated with reduced activity of molybdoenzymes. These enzymes include the primary nitrogen assimilation enzymes such as nitrate reductase (NR), and the nitrogen-fixing enzyme nitrogenase found in bacteroids of legume nodules. Other molybdoenzymes have also been identified in plants including xanthine dehydrogenase/oxidase involved in purine catabolism and ureide biosynthesis in legumes, aldehyde oxidase (AO) that is involved in ABA biosynthesis, and sulfite oxidase that can convert sulfite to sulfate, an important step in the catabolism of sulfur-containing amino acids Mendel and Haensch, (2002); Williams and Frausto da Silva, (2002).

There are recent review articles on molybdoenzymes in plants, animals and prokaryotes Mendel and Haensch, (2002); Williams and Frausto da Silva, (2002); that cover the extensive literature on the regulation and formation of Mo-CO and the activity of Mo-CO with molybdenum-dependent apoenzymes. Instead of re-examining this important component of molybdenum nutrition, this review will instead re-examine the effects of molybdenum nutrition in agricultural plants and explore the poorly understood aspect of molybdenum transport into and within the plant. In prokaryotes and lower-order eukaryotes, the molybdate transport systems have been well defined and are characterized at both the physiological, biochemical and genetic levels Mendel and Haensch, (2002) Williams and Frausto da Silva, (2002).

Translated into an improved understanding of how eukaryotic systems transport molybdenum. This is not surprising as the primary molybdate transport systems present in prokaryotes are members of the ATP-binding cassette (ABC) protein super family. Members of this super family extend into plants; however, the numbers are large, where in Arabidopsis alone there is predicted to be at least 129 putative proteins in the genome Bryson, (2014), Secondly, a large number of other putative transport proteins that may encode molybdate transport systems remain uncharacterized in sequenced plant genomes Gulber, (1982).Nevertheless, the prokaryotic systems are good starting points to discuss the types of eukaryotic systems that may exist and direct future research into specifically identifying plant molybdenum transport systems.

\section{1- Molybdenum Metabolism in Plants}

\section{Molybdenum and Enzyme Activity}

Plants require very small quantities of Mo, as compared to the 18 essential nutrients required for plant growth and development. An example of this is evident in comparison of Mo to other major and secondary nutrients, such as nitrogen. The adequate range of total nitrogen in muskmelon leaf tissue at the first growth stage (early runner) is 45.0-55.0 g. $\mathrm{kg}^{-1}$ Bryson, (2014), whereas, Mo concentration in healthy leaf tissue is just above $0.5 \mathrm{mg} \cdot \mathrm{kg}^{-1}$ or $0.0005 \mathrm{~g} / \mathrm{kg}$ Gulber, (1982). Although the required quantity of Mo is minimal, its metabolic role is substantial. Without Mo, plants would perish. Extensive research over the last 15 years has broadened our scientific understanding of the role of Mo in higher plants. Molybdenum research in higher-level plants has evolved from concepts learned in prokaryotes, such as bacterium, fungi, and unicellular algae Mendel et al., (1999). Molybdenum is a part of over sixty different enzymes Datta et al., (2011), known as molybdoenzymes. Less than ten types of 
molybdoenzymes are found in plants Mendel,( 2011). The primary role of molybdoenzymes is to catalyze oxidation-reduction reactions taking place within the carbon, nitrogen, and sulfur cycles of plants Kisker, (1997); Datta et al., (2011). Consequently, Mo plays a critical role in crop growth and development. Molybdenum uptake - from the soil into the plant root .The mode of Mo transport and absorption in higher plants is still under scientific debate. The two theories under consideration hypothesize that Mo uptake takes place through transporters located within plant roots, either through phosphate-phosphorus transporters Gupta, (1997); Datta et al., (2011), or sulfate transporters Mendel, (2011); Broadley et al., (2012).

Plant available Mo, molybdate, chemically bonds with phosphate-phosphorus to form a phospho molybdate complex within the soil. The phospho molybdate uptake through the roots is favored over phosphate-phosphorus ion uptake Haque, (1987). Phospho molybdate has greater solubility in water and greater availability in soil solution than phosphate phosphorus.

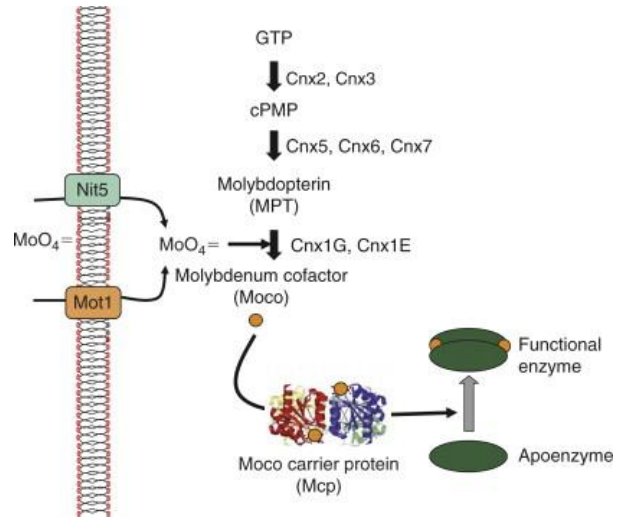

Fig. 3: Chemical structure of Tetra ammonium dioxo (phosphonato) molybdenumbis (olate) (Molecular Formular: $\mathrm{H}_{16} \mathrm{M}_{0} \mathrm{~N}_{4} \mathrm{O}_{7} \mathrm{P}$, Molecular Mass: 311.083401, Mon isotopic Mass: 312.9810685 )

The greater solubility enhances differential adsorption and requires less plant energy for nutrient uptake through the root system. Other researchers concluded that Mo uptake also might occur through the plasma membrane of plants root cells through phosphorus transporting sites Gupta (1997). However, other scientists have reported that Mo uptake is not affected by phosphorus transport sites. When soils contain adequate levels of available phosphate-phosphorus and low Mo, molybdenum uptake still occurs suggesting, other modes of Mo transport Kaiser et al., (2005).

Molybdenum transport proteins, such as MOT1, belong to the same family as other sulfate carriers. The role of MOT1 is to actively transport Mo into the roots and through the plant.

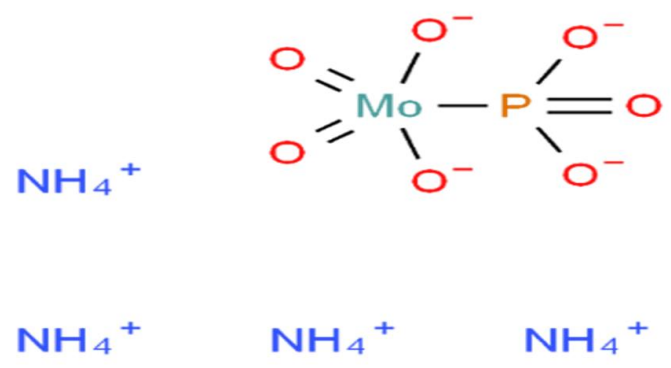

Fig. 4: Illustrate the important of MO-CO, as metabolic functions, in Nitrogen Utilization, in higher plants

This movement through the plant is accomplished by cellular membrane transport from cell to cell of the end membrane system Mendel, (2011). The relative molecular size of molybdate to sulfate is very similar Kaiser et al., (2005). Therefore, researchers speculate that Mo follows the same pathway as sulfate-sulfur. However, not all scientists agree. Past research has shown that sulfate-sulfur can block the uptake of Mo from the soil into the roots. Higher concentrations of sulfate-sulfur out compete Mo for sulfur transporters Broadley et al., (2012), possibly due to similar molecular size. Once inside the 
plant, molybdate is not biologically active. In order for Mo to bebiologically beneficial to the plant, this anion must be inserted into Mo-dependent enzymes, molybdoenzymes, for plant utilization. For this process to occur, it is essential that molybdate be first chemically transformed into a Mo-cofactor known as MO-CO.The biosynthesis of MO-CO is a four-step process that occurs within the cell's cytosol. This process involves multiple proteins, nitrogen, sulfur, phosphorus, copper, and in some casesiron Schwarz et al., (2006); Mendel, (2011). The chemical products from each biosynthetic step are cPMP, MPT, adenylate MPT, and Moco; respectively (Mendel, 2011). During the last step of Moco formation, Mo attaches to a specific pterin complex forming molybdopterin Schwarz et al., (2006); Mendel, (2011) as presented in Fig.(5).

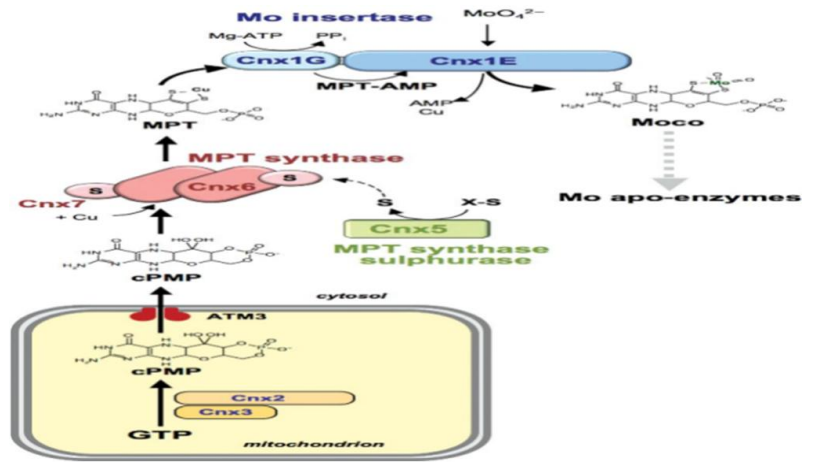

Fig. 5: Illustrate the biosynthesis of Moco in plants. The Moco pathway divided into four steps. The intermediates and the names of the $\mathrm{MO}-\mathrm{CO}$ biosynthesis enzymes are given.

(1) Biosynthesis starts with conversion of GTP to $C P M P$ in the mitochondria. The transporter ATM3 is involved in export of $c P M P$ to the cytosol.

(2) Heterotetrameric $M P T$ synthase, consisting of $C n x 6$ and $C n x 7$, inserts two sulphur atoms into $C P M P$ and converts it to MPT. MPT synthase receives the sulphur from $C n x 5$ (MPT synthase sulphur ase), with the primary sulphur donor of Cnx5 (X-S) being unknown. It is assumed that copper $(\mathrm{Cu})$ is inserted directly after dithiolene formation.

(3) $M P T$ is adenylated by the $C n x 1$ G-domain of Mo insertase Cnx1, thus forming MPT-AMP.

(4) MPT-AMP is transferred to the Cnxl E-domain where Mo is inserted by replacing $\mathrm{Cu}$, thus forming $M O-C O$ which is finally allocated to Mo apo-enzymes. For better readability, the colours used for drawing the respective enzymes are the same in all figures

\section{2-1 From Moco to molybdoenzymes}

Moco can follow two possible pathways, $(\boldsymbol{a})$ Moco is transported to the molybdoenzymes and inserted into the molybdoenzymes at the right time/right place; or $(\boldsymbol{b})$ Moco is attached to a carrier protein for protection, storage and, when required, be transported to a molybdoenzymes Mendel, (2011). Schwarz et al., (2006); Mendel, (2011). The supply and demand for Moco is what ultimately determines which pathway Moco will follow within higher-level plants. Without Moco, metabolic functions, such as nitrogen utilization, in higher-level plants would not occur. To complicate matters, Moco alone is very unstable and easily oxidized. Therefore, Moco must bind itself to proteins, specifically carrier proteins. When Moco becomes unstable, it disintegrates. In the disintegration process, Moco first separates from the carrier protein, then the Mo molecule dislodges from Moco and Mo becomes inactive. Last, the remaining components of Moco oxidize and are permanently rendered useless as Mo transporters Mendel, (2011). The final Mo anion pathway after it separates from Moco is unknown. Research on how Moco reaches the molybdoenzymes is incomplete; however, based upon unicellular algae observations, it is hypothesized that Moco-binding proteins lock onto and transport Moco to molybdoenzymes Schwarz et al., (2006); Mendel, (2011). Once Moco reaches its intended destination, incorporating Moco into molybdoenzymes begins. Unfortunately, the attachment site for Moco is not on the outer surface of the molybdoenzymes, but in the center heart of the molybdoenzymes. Using crystallographic analysis, the timing for the insertion of Moco into the molybdoenzymes takes place either at the very beginning or during the folding process of apoproteins, which are used to form the molybdoenzymes Mendel, (2011). The Moco and Moco-binding/transport protein complex contains all the components necessary to attach the Mo molecule to the precise location and alignment within the molybdoenzymes. Although Moco-binding/transport proteins aid in the attachment process Mendel, (2011), it is the pterin component that positions Mo directly into the molybdoenzymes activation site 
Schwarz et al., (2006). Pterin binds to Mo in the last step of Moco formation, thus, forming molybdopterin. Pterin not only delivers and positions the biological activating factor Mo to the molybdoenzymes, but pterin also regulates the activity of Mo within the molybdoenzymes Schwarz et al., (2006).General role of molybdenum in molybdoenzymes within molybdoenzymes, the purpose of Mo is to serve as the catalytic metal for oxidation-reduction (redox) reactions. Depending upon the functionality of the molybdoenzymes, Mo will either donate its electrons and become oxidized or accept electrons and have its oxidative state reduced Schwarz et al., (2006); Mendel, (2011). To help regulate and aid Mo in the redox process, pterin adjusts the pace of the redox chemical reactions as well as assists in electron transfer to and from Mo Schwarz et al., (2006). Breakdown of molybdoenzymes, is Mo recyclable? Once the redox reaction is complete, it is believed that molybdoenzymes disintegrate and Moco oxidizes as part of the breakdown process Mendel, (2011), similar to other enzymes. Although not confirmed, it is believed that Mo is not recyclable within the plant. Whether the Mo remains within the plant, exits via the stomata, or photosynthate deposits into the soil is unknown. Categorizing molybdoenzymes within higher-level plants, there are five known families of molybdoenzymes: nitrogenase, nitrate reductase, sulfite oxidase, aldehyde oxidase, and xanthine oxidase Haque, (2008). These families subdivided into two classes, excluding nitrogenase: (a) SO class, and (b) XO oxidase family, based upon the redox reaction Kisker et al., (1997); Mendel, (2011). The nitrogenase enzyme is maintained as separate, since it is found in nitrogen-fixing bacteria that form symbiotic relationships with plants in the legume family.

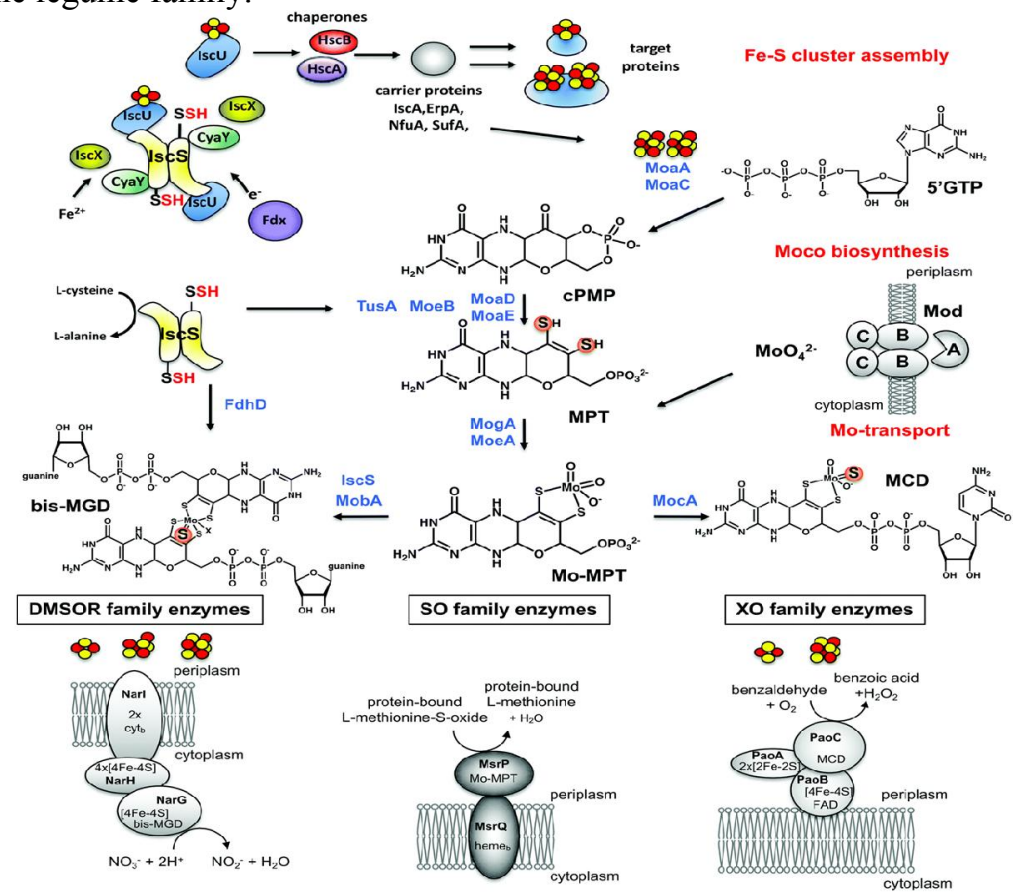

Fig. 6: Molybdoenzymes families, Moco biosynthesis and the link to Fe-S cluster assembly in E. coli. $\mathrm{Fe}-\mathrm{S}$ clusters are required for the activation of enzymes involved in Moco biosynthesis and for the activities of several molybdoenzymes. Fe-S clusters assemble on the scaffold protein IscU, which receives the sulfur from the L-cysteine desulfurase IscS.

The iron donor in this reaction has not been identified so far. CyaY and IscX are able to interact with the IscSIscU complex. Ferredoxin is delivering the electrons for Fe-S cluster assembly. Assembly and release of the clusters is catalyzed by the chaperones HscAB.

Different carrier proteins deliver the Fe-S clusters to acceptor proteins like MoaA, involved in the first step of Moco biosynthesis, or different molybdoenzymes. Molybdoenzymes, in general, are complex enzymes, containing additional cofactors like $\mathrm{Fe}-\mathrm{S}$ clusters or hemes.

Three different molybdenum-containing enzyme families exist in bacteria classified according to their coordination at the molybdenum atom: the xanthine oxidase, sulfite oxidase, and DMSO reductase families. The sulfite oxidase family is characterized by a di-oxo Moco with an additional protein ligand, which usually is a cysteine. The DMSO reductase family contains two MGDs ligated to one molybdenum atom with additional ligands being an oxygen or a sulfur, and a sixth ligand $\mathrm{X}$, which can be a serine, a cysteine, a selenocysteine, an 
aspartate or a hydroxide and/or water molecule. Shown is a scheme of the biosynthetic pathway for Moco biosynthesis. Mo-MPT is formed from $50 \mathrm{GTP}$ with cPMP and MPT as intermediates. The sulfur for the dithiolene group of Moco is derived from L-cysteine, mobilized by the IscS and transferred by TusA to the MPT synthase complex. Bis-MGD and MCD can be further modified by the addition of a sulfido-ligand at the Mo-active site, a reaction catalyzed by the L-cysteine desulfurase IscS. Molybdate is transported into the cell by the high-affinity molybdate transport system ModABC.

Examples for molybdoenzymes in E. coli are shown: NarGHI, nitrate reductase; MsrPQ, methionine-S-oxide reductase; PaoABC, periplasmic aldehyde oxidoreductase. After Arkadiusz Zupok et al. (2019)

\section{2-2 Nitrate reductase (SO-class)}

The most common form of nitrogen absorbed by plants is nitrate-nitrogen; however, higher-level plants cannot utilize nitrate directly. Nitrate must first be reduced by the molybdoenzymes nitrate reductase to form nitrite, and then reduced by a non-molybdoenzymes nitrite reductase, to form ammonium Gupta, (1997). For the purpose of this discussion, we will focus on molybdoenzymes. Nitrate reductase is located only in the cytosol of the plant cells Mendel, (2011).

This enzyme is positioned near chlorophyll molecules inside the chloroplast, for logistical nitrite
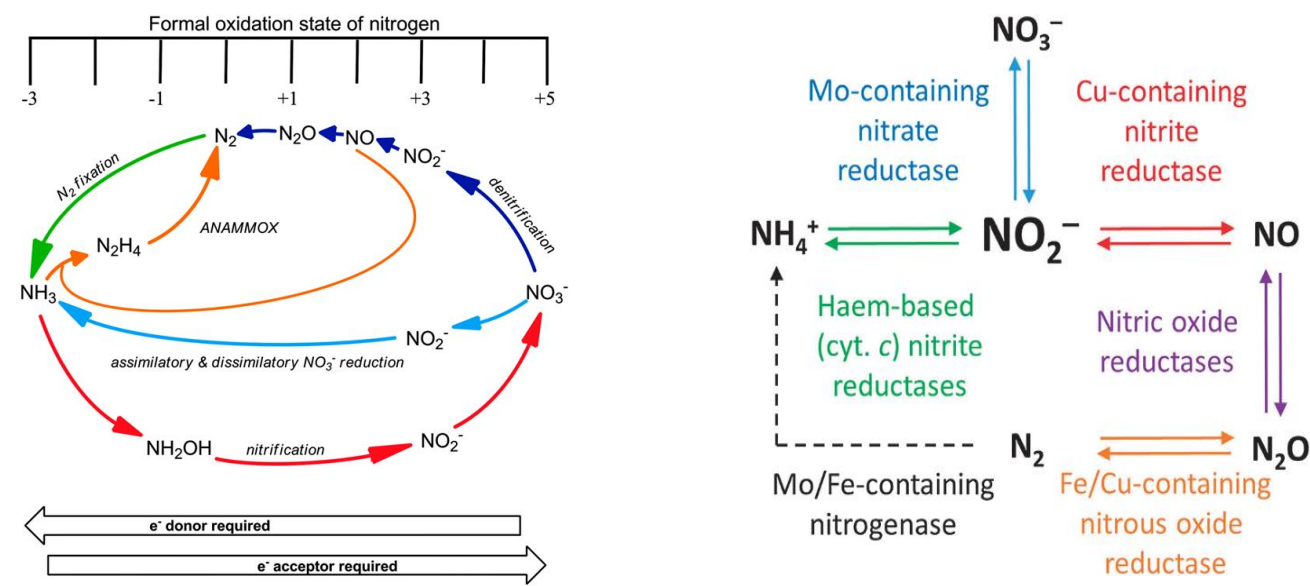

Fig. 6: Overview of the bacterial nitrogen cycle, showing the prominent positions occupied by the nitrogen oxides with some enzymes.

Transfer. It catalyzes a three-step catalytic cycle ending with Mo oxidization Mendel, (2011).

In the redo reaction, Mo donates an electron to nitrate, thus, reducing nitrate to nitrite and creating water as a byproduct:

$\mathrm{NO}_{3}-+2 e_{-}+2 \mathrm{H}+\rightarrow \mathrm{NO}_{2}-+\mathrm{H}_{2} \mathrm{O} \quad$ Schwarz et al., 2006) Mendel, (2011). .

Previous figure illustrates the bacterial nitrogen cycle, showing the prominent positions occupied by the nitrogen oxides (especially nitrite) with some enzymes, as simple as this may appear; nitrate reductase is an essential enzyme for plant health. Not only is nitrate reductase the first step in converting inorganic nitrate into organic nitrogen products, such as future plant proteins and DNA, but nitrate reductase is one of the initial steps in the nitrate assimilation process Kaiser et al., (2005). Nitrate assimilation is the transformation of inorganic nitrogen into organic forms utilized by plants. Therefore, nitrate assimilation is responsible for internal plant nutrition as well as the way the plants break down and utilize both carbon and nitrogen Mendel, (2011). The nitrate reductase concentration in plant cells corresponds directly to the concentration of Mo found in plant organelles Gopal et al., (2017); Nelson, (1984). Plants deficient in Mo continue to uptake nitrate-nitrogen from the soil and store the excess nitrogen within the leaf. When levels of nitrate-nitrogen within the plant tissue are high due to low Mo concentrations, a reduction of both chlorophyll and ascorbic acid may occur Bryson et al., (2014). Ascorbic acid protects the plant from oxidation damage caused during redox reactions, such as induced hydrogen peroxide formation and DNA breakage Datta et al., (2011), and allows the plant to adjust to abiotic stresses. Since nitrate-nitrogen continues to accumulate in the leaf, visual symptoms like chlorosis and leaf burn begin to develop at the leaf margin Kaiser et al., (2005). 


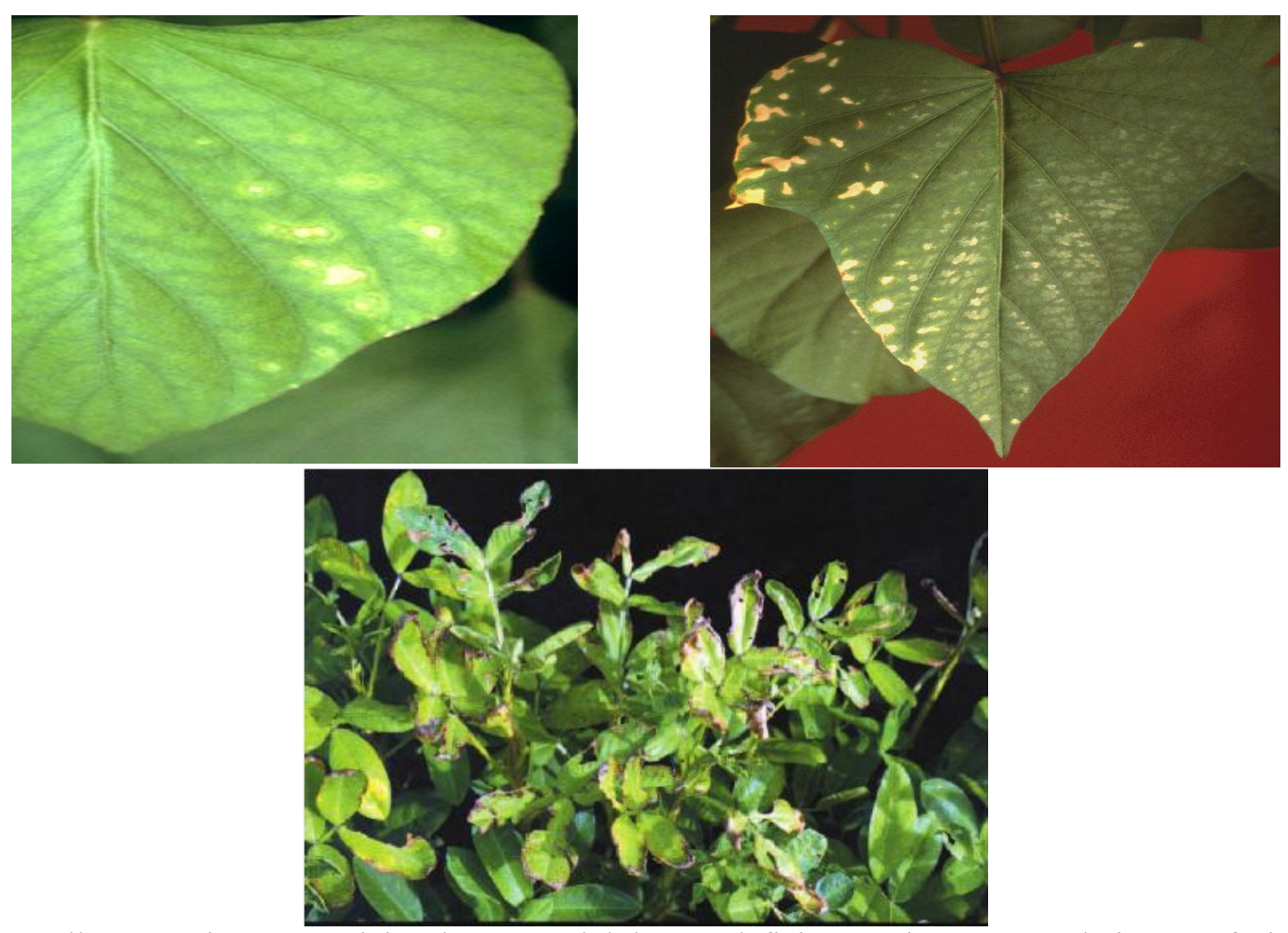

Fig. 7: Illustrate nitrogen toxicity due to Molybdenum deficiency, since accumulation of nitratenitrogen in the leaf; make visual symptoms like chlorosis and leaf burn begin to develop at the leaf margin after Kaiser et al., (2005)

This nitrate nitrogen accumulation also creates false 'adequate total nitrogen' readings in tissue analyses if Mo is over looked, leading to misdiagnosis of the true problem. As a result, plant growth and development will slow down and yield will be lost if the over accumulation of nitrate nitrogen is not rectified.

Bao-Ming et al. (2004) reported that more and more nitrogen fertilizers are applied in fields, $\mathrm{N}$ fertilizer plays a significant role in both crop yield and quality Sisson et al .(1991) Wang et al .(2002). Nitrate is often the major source of $\mathrm{N}$ available to higher plant Marschner (1995), especially, to vegetables. Nitrate uptake and distribution in crops is of major importance with respect to both environmental concerns and the quality of crop products. Nitrate, not taken up by a crop, may potentially contribute to ground and surface water pollution through nitrate leaching and soil erosion Gastal and. Lemaire (2002), Wang et al. (2002).

On the other hand, nitrate taken up by plants causes high nitrate accumulation in plants, especially, in most vegetables. Because edible parts contain very high concentrations of nitrate that have been implicated in the occurrence of methaemoglobinemia and possibly in gastric cancer as well as other diseases Bruning-Fann and. Kaneene (1993), Ishiwata, et al .(2002). Nitrate accumulation in plants is a major concern, and is a problem in most crops Van der Boon et al. (1990), Cárdenas-Navarro et al. (1999). Although higher plants are capable of reducing $\mathrm{NO}_{3}$ in both roots and shoots Marschner (1995), nitrate is reduced more efficiently in leaves than in roots because of the readily available reductants, energy and carbon skeletons produced by photosynthesis, which is dependent on plant species Solomonson, et al. (1990), Oaks (1994).

This is also true for most leafy vegetables, nitrate taken up by a plant is either reduced or stored in the vacuoles or transported in the xylem transpiration stream to the leaf for reduction, and most is stored in the vacuole until released for reduction in the cytosol Cárdenas-Navarro et al. (1999). In addition, NR exists in the cytosol; therefore, nitrate in cytosol is called the nitrate metabolic pool (MP), and nitrate in the vacuole is called the nitrate storage pool (SP) Ferrari et al .(1973), Miller, A.J., S.J. Smith, (1996). Since NR is assumed the rate-limiting step for nitrate assimilation Caba et al. (1995) Bussi, et al. (1997), and the NR is an inducible enzyme. There is a close relationship between NR activity (NRA) and nitrate concentration in plants Skrdleta et al. (1979). Furthermore, nitrate induces 
the expression of both the uptake and reduction systems Sivasankar et al. (1997).Thus, it can be seen that nitrate accumulation might be regulated by many factors, such as plant growth, endogenous nitrate, and nitrate uptake and reduction.

\section{2-3 Sulfite oxidase (SO-class)}

Sulfite oxidase has occurred using chicken livers Schwarz et al., 2006; Mendel, (2011) because, in the Kingdom Animalia, SO detoxifies the body preventing premature death in humans Kappler et al., (2014). However, within the last twelve years, scientists have learned that there are significant differences between sulfite oxidase in the kingdom Animalia versus the kingdom Plantae; scientists are still making headway. Sulfite oxidase in chicken liver resides in the mitochondria. However, in higher level plants sulfite oxidases are found inside peroxisomes within the cytoplasm of plant cells, not in the chloroplasts as originally hypothesized Schwarz et al., (2006); Mendel, (2011). To prevent sulfite toxicity within the plant, the plant produces the molybdoenzymes, sulfite oxidase. The primary function of Mo in sulfite oxidase is to act as the catalyst in the reaction of oxidation-reduction through oxidizing sulfite to sulfate and hydrogen peroxide Schwarz et al., (2006); Mendel, (2011); Broadley et al., (2012). Since sulfite, reductase is encased within the peroxisomes, the peroxisomes breakdown hydrogen peroxides and produces free radicals before the byproducts can cause physical damage within the plant cell Schwarz et al., (2006).

Two main sources of sulfite accumulation in plants, first is through the breakdown of sulfur dioxide, which is a noxious gas produced globally as a byproduct of fossil fuel burning. Natural processes, such as microbial respiration and geological activity Schwarz et al., (2006); Brychkova et al., (2007) and Broadley et al., (2012). Sulfur dioxide enters the plant through the stomata openings in the leaf. Consequently, as the number of open stomata increases, so does the concentration of sulfur dioxide entering the plant Brychkova et al., (2007) Fig. (8). Sulfite oxide, can also produce in fermentation, as well as released from degradation of sulfur-based amino acids in higher-level plants Schwarz et al., (2006); Brychkova et al., (2007); Broadley et al., (2012).

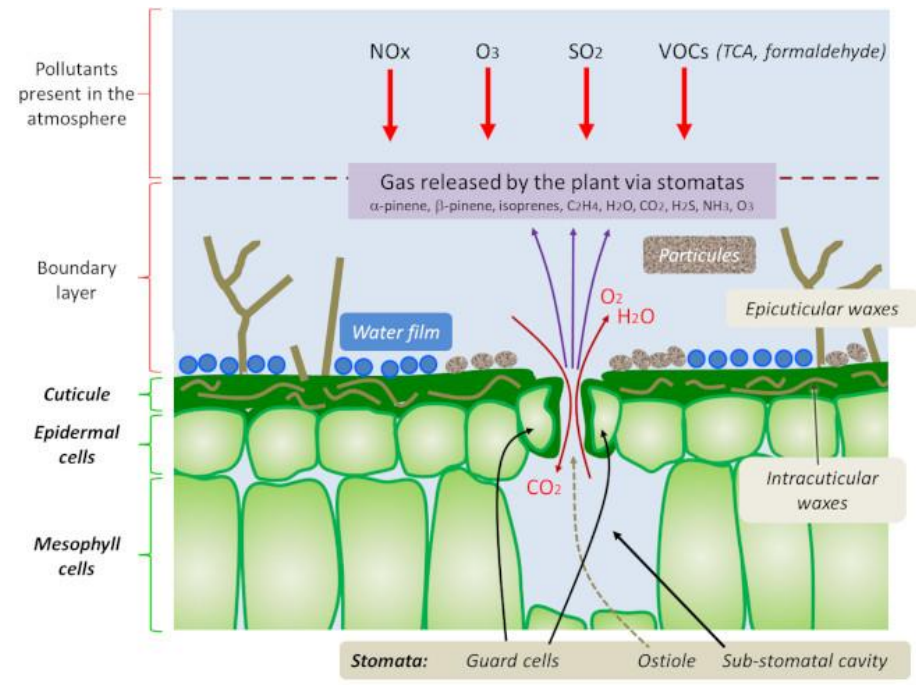

Fig. 8: Represent schematic presentation of the environment of leaves penetration

Although higher plants utilize small concentrations of sulfur dioxide for growth and development, elevated can cause internal cell damage. Visual effects seen in the field from sulfur dioxide toxicity are chlorosis due to chlorophyll damage, which can lead to lower crop yields and plant death Brychkova et al., (2007) Fig.(9). 
A

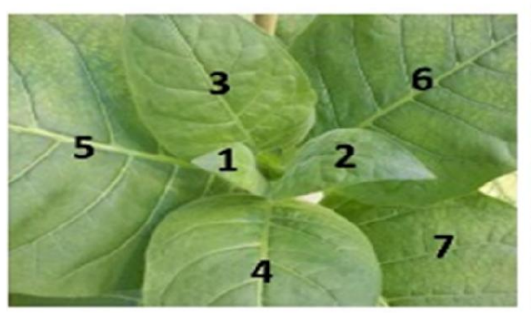

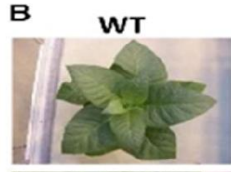
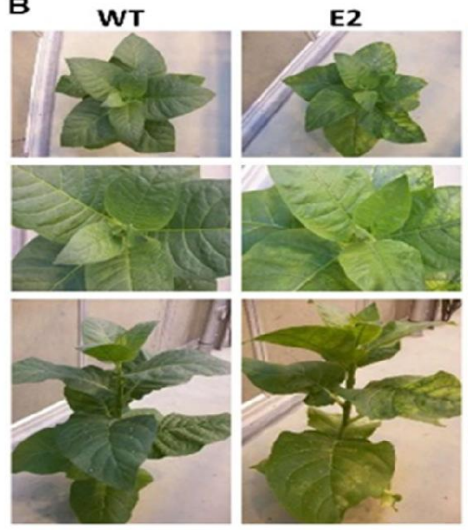
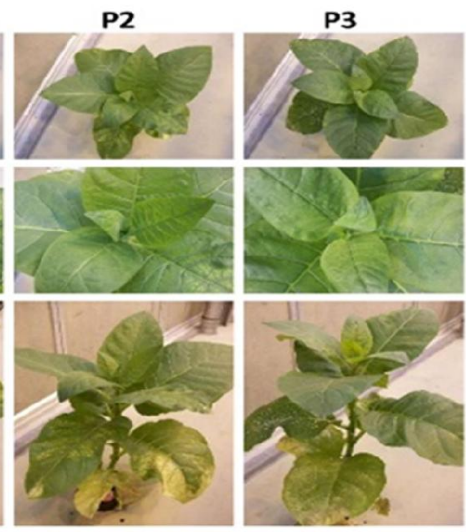

Fig. 9: Sulfite reductase (SIR) co-suppression tobacco lines.

(A) Leaf numbering indicates the consecutive numbering of leaf samples for harvesting from youngest leaf (L1) to oldest leaf harvested (L7).

(B) Tobacco plants at the harvesting stage (approximately 2-month-old plant). Each panel shows a representative plant. Starting with L5 leaf chlorosis becomes visible. The phenotype actually resembles that of sulfate starvation as around vasculature tissue remains greener than between veins. In some cases, a retarded growth phenotype was observed. This P2 plant displays strong chlorosis and necrosis associated with older leaves. After Marcel Neumann (2018)

Irrigated crops in fields with low water penetration, can be consider as waterlogged soil, as well as peat-based mediums are more susceptible to sulfite toxicity Hara, (2016). The waterlogged soils created anaerobic condition. Under such condition, anaerobic bacteria reduce sulfate to plant-toxic hydrogen sulfite gas. Aldehyde oxidase (XO oxidase family) higher level plants biosynthesize phytohormones to help and regulate plant growth. Phytohormones, such as abscisic acid (ABA) and indole-3-acetic acid (IAA), require the molybdoenzymes aldehyde oxidase Engels, et al., (2012). Within the cytosol of the plant cell, the Mo component of aldehyde oxidase acts as the catalyst in the redox reaction.

$$
\mathrm{R}-\mathrm{CHO}+\mathrm{H}_{2} \mathrm{O} \rightarrow \mathrm{R}-\mathrm{COOH}+2 \mathrm{H}^{+}+2 \mathrm{e}^{-} \quad \text { Kaiser et al., (2005); Mendel, (2011). }
$$

In relation to $\mathrm{ABA}$, the aldehyde oxidase redox reaction takes place during the final phase of biosynthesis. Mo oxidizes the organic compound abscisic aldehyde forming ABA Schwarz et al., (2006); Yan et al., (2016). One of the many functions of ABA is to alert the other plant organelles of the environmental stress that will reduce growth and development. This allows plant to respond appropriately and conserve internal resources to minimize tissue damage. For example, under drought conditions when the soil moisture is near plant wilting point, the roots will produce more ABA and transport ABA through the xylem to the leaves Engels, et al. (2012). Once the leaves receive the ABA signal the stomata close to reduce water loss. Without the molybdoenzymes aldehyde oxidase, plants would wilt and yields possibly decreased. Variable ABA concentrations also influence other plant responses to environmental stimulus. Plants with low ABA are often more sensitive to temperature changes, an aerobic conditions, and saline soils, as well as produce less viable offspring Mendel, (2011). Broadley et al., (2012).

Abscisic acid ABA plays an important role during seed maturation and seed dormancy. ABA is one of two phytohormones that choreograph protein and lipid storage within seeds and allows seed to remain in a dormant state until conditions are adequate for germination Yan et al., (2016). Low Mo concentrations during this phase will prevent the future offspring from containing all the nutrients required for seed germination. The second phytohormones, IAA, is a hormone growth regulator used to control most biological processes within the plant Abdoli et al., (2013). Since IAA is in the auxin family, research suggests that aldehyde oxidase plays a more crucial role in IAA formation during the early development phases of higher-level plant life cycles Mendel, (2011). Indole-3-acetic acid IAA regulates the development of the plants vascular system, promotes cellular elongation, root growth, and aids in increasing plant height by increasing apical dominance, thus, reducing lateral growth Mendel, (2011). Abdoli et al., (2013). Increased concentration of IAA also promotes plant growth by enlarging 
the plant leaves and aids in the transport of carbohydrates from the leaf to organelles Abdoli et al., (2013). Decreasing aldehyde oxidase can lead to reducing leaf area index (LAI) as well as a reduction in plant sugar formation; i.e. lower brix values. Xanthine dehydrogenase the exact function of the molybdoenzymes, xanthine dehydrogenase, in higher-level plants is still unclear. Most of the xanthine dehydrogenase research over the last few decades has focused efforts in the kingdom Animalia; specifically, within bovine milk Mendel, (2011). The understanding of xanthine dehydrogenase in bovine milk has allowed scientists to confirm as well as disprove similar observations in higher-level plants. What scientists have learned is that xanthine dehydrogenase is localized in both the cytosol and peroxisomes.

Xanthine dehydrogenase has three plant functions:

(A) Aid in the formation of NADH

(B) Break down purines, the building blocks of DNA and RNA, to form uric acid

(C) Produces superoxides Mendel, (2011). Since xanthine dehydrogenase controls the production of NADH and superoxides, some scientists hypothesize that xanthine dehydrogenase affects the ratio of $\mathrm{ADH} / \mathrm{NAD}^{+}$used in the redox reaction for cellular electron transfer Mendel et al., (1999); Schwarz et al., (2006); Mendel, (2011).

\section{3-Factors affecting nodulation formation}

\section{3-1 Molybdenum}

Molybdenum (Mo), is an essential micronutrient, plays an important role in nitrogen $(\mathrm{N})$ metabolism and protein synthesis in plants. During symbiotic $\mathrm{N}$ fixation, Mo acts as a cofactor for nitrogenase enzymes to catalyze the redox reaction to convert elemental $\mathrm{N}$ into ammonium $\left(\mathrm{NH}^{+4}\right)$ ions Mendel and Hänsch (2002). Nitrate reductase enzymes required for $\mathrm{N}$-assimilation source of nitrates particularly, in soil. Therefore, plant N- metabolism is closely related to the Mo concentration in soil, especially for leguminous plants Mendel and Hänsch (2002). Due to this relationship, Mo-deficient legumes show an unusual proliferation of nodules, which in turn leads to $\mathrm{N}$ deficiency Marschner (2011). Cultivation of winter cover crops to agricultural soils as a source of organic matter is a popular practice in several countries, especially in temperate regions. Hairy vetch (Vicia villosa Roth), a leguminous cover crop, is used as a green manure for maintaining soil fertility that reduce chemical fertilization Pramanik et al. (2013). Leguminous plants, hairy vetch has rhizobium bacteria in root nodules that require Mo to fix atmospheric $\mathrm{N}$ as a plant-available form Campo et al. (2000). Molybdenum is involved in the biochemical processes catalyzed by nitrogenase (NA) and nitrate reductase (NR), and indirectly affects crop biomass production Ingle (1966).

Nitrogen is the major nutrient for plant growth, and biological N- fixation in soil may reduce chemical fertilizer load for crop production Islam et al. (2013). Many environmental factors such as soil conditions Pramanik et al. (2013). Nitrogen and phosphorus (P) levels Drew and Ballard (2010) soil types Pramanik et al. (2013). and soil management practices Drew and Ballard (2010) gradually influence the efficiency of biological nitrogen fixation (BNF). Solaiman (1999) found that application of Mo at rate of $1.5 \mathrm{~kg} \mathrm{ha}^{-1}$ with Brady rhizobium inoculant increased nodule numbers, nodule weights and yields of soybean. Malla et al. (2007) reported that application of Mo $\left(1.5 \mathrm{~kg} \mathrm{ha}^{-1}\right)$ increased the yield of pigeon pea (Cajanuscajan). Seed priming with Mo $\left(0.5 \mathrm{~g} \mathrm{~L}^{-1}\right.$ solution of sodium molybdate) for $8 \mathrm{~h}$ increased yield of chickpea (Cicer arietinum) 27\% in pot study and 20\% in field study Farook et al. (2012). Previous studies showed large variations in BNF efficiency both between (Anugroho et al. 2010) and within Drew and Ballard (2010) cover crop species. Among different rhizobial genotypes, some strains have higher BNF ability in leguminous cover crops than in the others Drew and Ballard (2010). Pramanik et al. (2013) found that changes in nodule characteristics influence hairy vetch growth, and Haque et al. (2013) observed that hairy vetch growth determines the amount of $\mathrm{N}$ assimilated by cover crop biomass.

Faridul Alam et al. (2015) reported that Mo is an important for biological N-fixation in soil, acts as the central metal ion in the cofactors for both NA and NR enzymes Mendel and Hänsch (2002). Stated that, application of molybdenum proportionately increased both number and weight of nodules in hairy vetch roots; however, nodule characteristics in plants gradually decreases when treated with $1.0 \mathrm{mg} \mathrm{kg}{ }^{-1}$ molybdenum. This observation might be attributed to the fact that plants require minute quantities of micronutrients, and higher quantities inhibit plant growth Gungula and Garjila (2006); 
Jabbar and Saud (2012). Symbiotic N-fixing bacteria such as Rhizobium species convert atmospheric $\mathrm{N}_{2}$ into ammonium-N and nitrate-N forms involving NA enzymes in the nodules of leguminous plants, which molybdenum plays an important role in this biochemical redox reaction. Molybdenum treatments significantly $(\mathrm{P} \leq 0.05)$ increased NA activity in hairy vetch, which in turn proportionately increased Nfixation by molybdenum treated plants. Vieira et al. (1998) revealed that adequate of available molybdenum in the soil increases gradually stimulate $\mathrm{N}$-fixing potential of nodules reflecting, on physical and biochemical characteristics of nodules and furthermore, high positive correlation with $\mathrm{N}$ uptake and biomass of hairy vetch plants were noticed. Pramanik et al. (2013) observed that changes in the number and weight of nodules in hairy vetch and its NA activity were directly related to the nitrate$\mathrm{N}$ content in soil. Nitrate reductase activity was dependent on the total root biomass and available nitrate-N content in the soil. Nitrate reductase activity in treated plants with molybdenum showed a significantly $(\mathrm{P} \leq 0.05)$ positive correlation with the number and weight of nodules, total biomass yield, Mo content and $\mathrm{N}$ content. The final product $\left(\mathrm{NO}_{3}-\mathrm{N}\right)$ of $\mathrm{NA}$ is the precursor for the NR reaction and, therefore, NA and NR activities were significantly correlated $(r=0.903)$ in hairy vetch. However, Nautiyal and Chatterjee (2004) and Men and Li (2005),proposed that decreasing of NR activity might be explained by differences in the $\mathrm{NO}_{3}-\mathrm{N}$ to ammonium-nitrogen $\left(\mathrm{NH}_{4}-\mathrm{N}\right)$ ratios in plants or distortions in root cells owing to high rates of molybdenum application. Liu (2002) also observed those changes in cell morphology and a reluctance of leguminous plants to uptake molybdenum in high- molybdenum treatments. The relative NA and NR activities determine the enrichment of nitrate-N content in rhizosphere soil Pollock et al. (2002). Faridul Alam et al. (2015), observed that highest $\mathrm{N}$ content and $\mathrm{N}$ uptake after treatment with $0.5 \mathrm{mg}$ molybdenum $\mathrm{kg}^{-1}$ due to higher $\mathrm{N}$ assimilation, although they, recorded the highest NR in those plants. Therefore, injudicious application of molybdenum might cause plant biomass loss by retarding NA and NR enzyme activity in hairy vetch Jones ( 1998); Raven et al. (1999), and application of $0.63 \mathrm{mg} \mathrm{Mo} \mathrm{kg}{ }^{-1}$ soil is expected to maximize the crop yield (5.16 $\left.\mathrm{g} \mathrm{plant}^{-1}\right)$ by improving the biochemical properties of hairy vetch (see Supplementary Material). The NA enzyme in $\mathrm{N}$-fixing bacteria consists of the Mo-Fe protein responsible for the reduction of atmospheric $\mathrm{N}$ during the $\mathrm{N}$ fixation process Lambers et al. (1998), and symbiotic Rhizobium species require approximately 10 times more molybdenum for $\mathrm{N}_{2}$ fixation than do host plants for protein synthesis Thibaund (2005). The 16S rRNA genes are phylogenetic markers characterized by functional diversity, evolutionary information and variable structural elements Ludwig and Klenk (2001). We detected Rhizobium strains such as $R$. leguminosarum (strain CIAM 97), $R$. leguminosarum (strain SEMIA 3018) and A. tumefaciens (strain bG52) in plants treated with all tumefaciens doses, including the control. Hou et al. (2009) and Tian et al. (2010) also observed a large abundance of $R$. leguminosarum in nodules of leguminous plants. Optimum molybdenum application improved nodule characteristics in hairy vetch plants, and these characteristics may have enabled the presence of Rhizobium species similar to A. tumefaciens. The bacterial species play a role for improving enzymatic activity in nodules, which enhanced $\mathrm{N}$ uptake and increased the biomass of hairy vetch. Therefore, the optimum molybdenum application increased biomass productivity by improving nodule characteristics and enhancing $\mathrm{N}$ uptake by leguminous plants.

\section{3-2 Iron}

Iron is required for several key enzymes of the nitrogenase complex as well as for the electron carrier ferredoxin and for some hydrogenases. A particular high iron requirement exists in legumes for the heme component of hemoglobin. Therefore, in legumes iron is required in a greater amount for nodule formation than for host plant growth, for example in lupins Tang, et al .(1990) and peanut Fig. (10). 

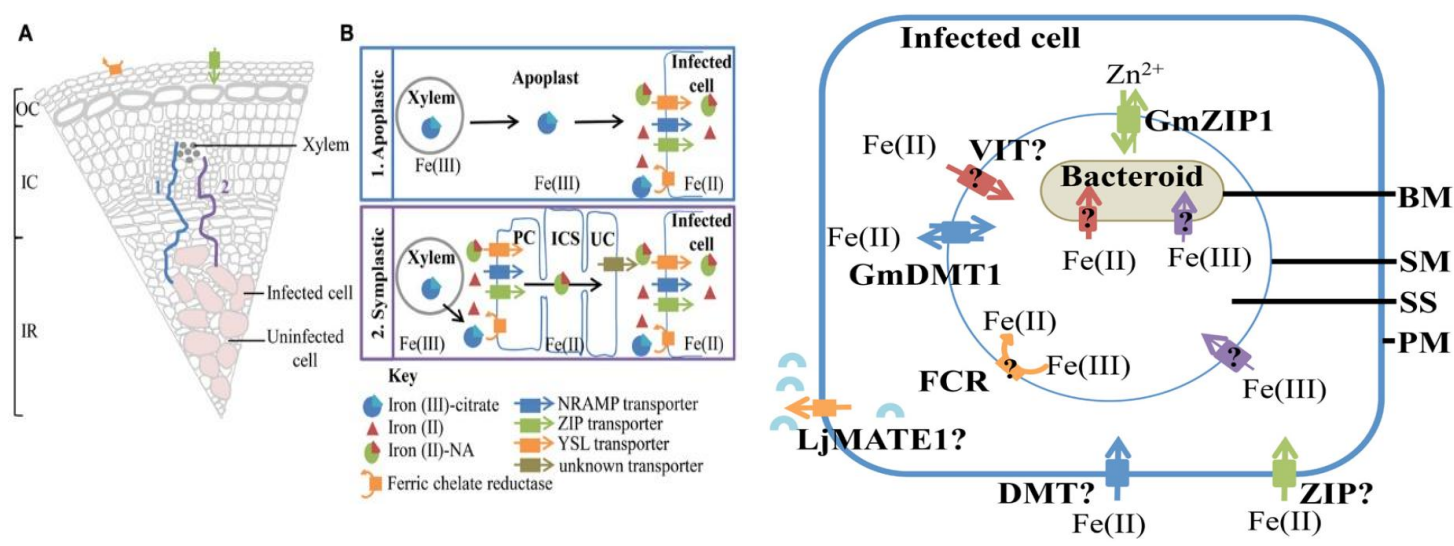

Fig. 10: A Summary of Possible Transport Pathways for Fe from the infected cell (A). Moreover, more detailed depiction iron of iron and transporters involved (B).After Ella et al. (2014)

Ella et al. (2014) reported that ferrous iron transport into the infected cells, across the plasma membrane (PM) could be mediate by transporters belonging to the NRAMP, Zip or YSL family. Acitrate effluxes, LJMATEI is expressed in infected cells, it is predicted release citrate (Blue arc) into the apoplast surrounding infected cells to aid in iron uptake. It is likely to make iron in the apoplast more soluble. Both ferrous and ferric iron are transported across the symbiosome membrane(SM) and bacteroids membrane (BM).However, ferrous iron taken up more rapidly. Ferric iron transporters GmDMTI, is presented on the SM, but it may not be the only ferrous iron transporter on the SM.Members of VIT and ZIP transporter families are possible ferrous iron on the transporters on sthe SM. Although ferric iron is thought to cross the SM, no plant transporters are known to transport iron citrate. Ferric chelate reductase activity (FCR) is presented on the SM; however, the orientation on the SM has not been confirmed. With the symbiosome space, (SS) ferric iron could chelate siderophores produced by bacteroids. Ferrous and ferric iron are transported across the bacteroids membrane (MB), but the transporters have not been identified

A reduction in specific rates of nitrogenase activity has been observed in $\mathrm{Fe}$ limited peanut nodules Hara et al. (1988), indicating a possible direct limitation by Fe deficiency on nodule function. Leghemoglobin is an oxygen-binding protein. The single most abundant protein that the plant host makes in the nodule is leghemoglobin, an iron protein. In the bacteria, nitrogenase and nitrogenase reductase contain FeS clusters and the former has the cofactor Fe-Mo-Co at the active site for $\mathrm{N}_{2}$ reduction Fig. (11).

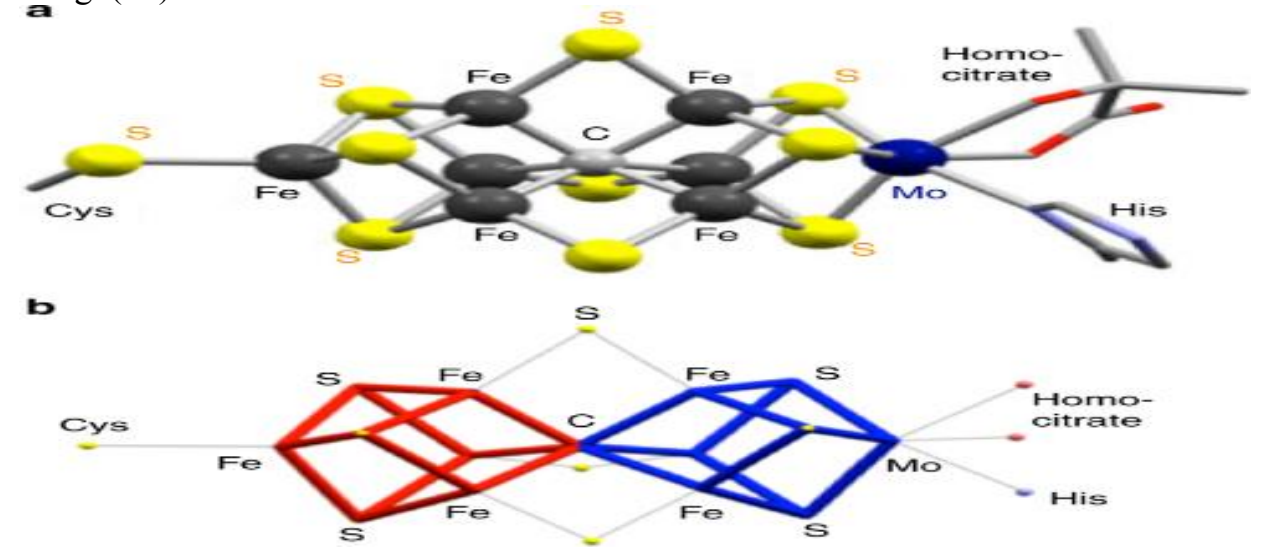

Fig. 11: Structure of the nitrogenase Fe Mo-cofactor.

(a) The resting-state structure. The peptide chains of cysteine (Cys) and histidine (His), as well as a part of (R)homocitrate are omitted for clarity. Color legend: $\mathrm{C}$, gray; Fe, black; Mo, dark blue; $\mathrm{S}$, yellow; $\mathrm{O}$, red; N, light blue.

(b) Wire-frame drawing of the inorganic part of the Fe Mo-cofactor, which highlights the fused form of the two cubes 
Further, bacteroids have a very high respiratory demand, requiring abundant cytochromes and other electron donors, each with their own Fe centers Delgado et al. (1988). Although iron deficiency did not significantly affect shoot growth, it severely depressed nodule mass and particularly, leghemoglobin content, number of bacteroids and nitrogenase activity, compared with those plants five days after a foliar spray of iron. In contrast to peanut, in Lupin (Lupinus angustifolius) iron is not translocated into the nodules after a foliar spray and direct iron supply at the infection sites at the roots required for effective nodulation Tang, et al. (1990). In lupin and peanut, nodule development is much more susceptible to a shortage of Fe than are other parameters such as plant shoot and root weights, Hara et al. (1988). Its relevance to $\mathrm{N}_{2}$ fixation is clear, given that the $\mathrm{Mo}$ in (Fe- Mo- Co) cofactor is at the heart of the nitrogen reduction process at least for most nitrogenases. The Mo-Fe protein contains two atoms of molybdenum and has oxidation-reduction centers of two distinct types: two ironmolybdenum cofactors called Fe- Mo- Co and four Fe-S (4Fe-4S) centers. The Fe-Mo cofactor (Fe$\mathrm{Mo}-\mathrm{Co}$ ) of nitrogenase constitutes the active site of the molybdenum-containing nitrogenase protein in $\mathrm{N}_{2}$-fixing organisms Allen, et al. (1999). Although at low supply, molybdenum is preferentially transported into the nodules Brodrick and Giller, (1991), molybdenum deficiency-induced nitrogen deficiency in legumes relying on $\mathrm{N}_{2}$ fixation is widespread, particularly, in acid mineral soils of the humid and sub humid tropics

\section{3-3 Effect of lime on Nitrogen fixation}

Calcium supplied to plants through lime may perform multiple functions in plants. They are essential component in symbiotic $\mathrm{N}_{2}$-fixation and nodule formation in legumes. Studies have indicated that calcium deficiency in legumes depressed the calcium content of nodules, impairing nitrogen fixation due to inadequate calcium for nodule structure and/or metabolism Banath et al., (1996); Graham, (1992). In this context, $\mathrm{Ca}^{2+}$ deficiency in legume decreased the supply of fixed nitrogen from nodules to other organs, thus, impairing plant growth. With regard to molybdenum, it is known to have a notable influence on nitrogen metabolism in $\mathrm{N}_{2}$ fixing legumes Franco and Munns, (1981); Prker and Harris, (1977); Marschner, (1995); Vieira et al., (1998). In modulated legumes, Molybdenum is necessary for the reduction of atmospheric nitrogen $\left(\mathrm{N}_{2}\right)$ to ammonia by nitrogenase enzyme. The symbiotic bacteria require about ten times more molybdenum for $\mathrm{N}_{2}$-fixation than does the host plant (for protein synthesis). For this reason, Mo deficiency will commonly occur in legumes before it does in other plants when grown in the same soil Thibaund, (2005). Karimian and Cox, (1978), stated that alkalinity stimulate the mobility and bioavailability of Molybdenum. Gupta, (1997), reported that availability of molybdenum is $\mathrm{pH}$-dependent. In fact, for every unit increase in soil $\mathrm{pH}$, Mo availability within the soil increases one-hundred-fold. Molybdenum is classified as a micronutrient; however, the inverse relationship between Molybdenum availability and soil $\mathrm{pH}$ is opposite to most other micronutrients. Alkaline soil $\mathrm{pH}$ allows molybdenum to adsorb readily to cations such as calcium, sodium, potassium, and magnesium. This process increases the available molybdenum concentrations for immediate plant uptake and Molybdenum losses through leaching Kaiser et al, (2005). Molybdenum is essential for nitrate reductase and nitrogenase enzyme activity Westermann, (2005). The symbiotic bacterial enzyme nitrogenase is comprised of Mo Fe protein, which is directly involved in the reduction of $\mathrm{N}_{2}$ to $\mathrm{NH}_{3}$ Lambers et al., (1998) during fixation process. Supply of molybdenum to bacteroids is therefore an important process and most likely a key regulatory component in the maintenance of nitrogen fixation in legumes that may influence plant growth Kaiser et al., (2005). When leguminous plants are grown under molybdenum deficiency conditions, phenotypes with hindered and/or retarded plant growth characteristics may develop. Most of these phenotypes may be associated with reduced activity of molybdoenzymes Agarwala and Hewitt, (1954); Spencer and Wood, (1954); Afridi and Hewitt, (1965); Randall, (1969); Jones et al., (1976); Agarwala et al., (1978). These enzymes include the primary nitrogen assimilation enzymes such as nitrate reductase (NR) and the nitrogen-fixing enzymes (nitrogenase) found in bacteroids of legume nodules Vieira et al., (1998). Other molybdoenzymes have also been identified in plants including xanthine dehydrogenase/oxidase involved in purine catabolism and ureide biosynthesis in legumes, aldehyde oxidase and sulfite oxidase Mendel and Haensch, (2002); Williams and Frausto da Silva, (2002). It can be concluded that, molybdenum deficiency is primarily associated with poor nitrogen health in plants and ultimately impaired growth. Research reports have indicated the stimulating influence of Mo in $\mathrm{N}_{2}$-fixation in legumes. In their research, Gurley and Giddens (1969), Franco and Munns (1981), Ishizuka (1982), and 
Brodrick and Giller (1991) showed that Mo supply in legumes increased molybdenum concentrations in nodules, improving $\mathrm{N}_{2}$-fixation, development of seeds and other tissues. Experiments with soybean and common bean have also shown that molybdenum fertilization enhanced nitrogen-fixing symbiosis through increased nitrogenase activity rates and larger nodule formation Brodrick and Giller (1991); Adams, 1997; Vieira et al., 1998).

\section{Adaptive mechanisms with drought stress}

\section{4 -1- Through enhancing antioxidant defense}

Drought stress is a major environmental stress that limits plant growth and crop production. However, plants have developed various complicated adaptive mechanisms to cope with drought stress by triggering a series of physiological and biochemical responses $\mathrm{He}$ et al., (2015). Among these mechanisms, antioxidant defense plays a crucial role in the alleviation of damage caused by drought stress Wu et al., (2014); Wu S. et al., (2015). Phytohormones and signal molecules are involved in the regulation of antioxidant defense, and both play vital roles in the perception and transduction of signals induced by drought stress Elisabeth et al., (2014). The signals activate antioxidant enzymes to destroy reactive oxygen species (ROS), which contributes to the maintenance of membrane integrity and thus, confers drought tolerance to plants. As a stress-resistance element. Molybdenum (Mo) has been extensively reported to facilitate the improvement of abiotic stress tolerance against salinity, low temperature and water stress in plants Sun et al., (2009); Zhang et al., (2012); Sun X. et al., (2014); Wu et al., (2014). Among the mechanisms underlying tolerance improvement in plants, improvement of antioxidant defense by Mo is a crucial strategy for plants to adapt to abiotic stresses. However, little is known about the potential mechanism by which Mo improves antioxidant defense under abiotic stresses, particularly drought stress.

As a Mo-enzyme, that catalyzes the reduction of nitrate to nitrite Babenko et al., (2015), nitrate reductase (NR) also plays a key role in nitrogen $(\mathrm{N})$ assimilation. In addition, NR is involved in the production of signal molecule nitric oxide (NO), and NR-dependent NO production increases the ability of nitrogen uptake Sun et al., (2015). In plants, there are two main pathways to produce nitric oxide reduction of nitrite to NO by NR and oxidization of arginine by nitric oxide synthase (NOS) Elisabeth et al., (2014). More recently, it was suggested that the Mo-enzymes NR and amidoxime-reducing component (ARC) could form a dual system of NR-ARC to induce NO production under nitrate in Chlamydomonas Chamizo-Ampudia et al., (2016). NO plays crucial roles in plant growth, development and response to various environmental stresses Sanz et al., (2015). There are growing evidences suggesting that $\mathrm{NO}$ interacts with abscisic acid (ABA), hydrogen peroxide $\left(\mathrm{H}_{2} \mathrm{O}_{2}\right)$, brassinosteroid (BR) and other cellular mediators in response to abiotic stresses Zhang et al., (2011); Lu et al., (2014); Sanz et al., (2015); Chen et al., (2016).

NO improves seminal root elongation, which is involved in the regulation of strigolactone under nitrogen-deficient and phosphate-deficient conditions Sun et al., (2016). NO in guard cells regulates $\mathrm{KC}$, anion fluxes by ion channels, and it is required for ABA-induced stomatal closure in Arabidopsis Chen et al., (2016). NO acts downstream signal of auxin to trigger root ferric-chelate reductase activity in response to iron deficiency in Arabidopsis Chen et al., (2010). Besides, NO is involved in the improvement of oxidative stress tolerance by inducing antioxidant defense under aluminum (Al) stress in wheat roots Sun. et al., (2014), water stress in maize Sang et al., (2008a), and heat stress in reed Song et al., (2006). Calcium-calmodulin plays a role in both upstream and downstream signal of NO signal in ABA-induced oxidative tolerance in maize Sang et al., (2008b). It has also been suggested that mitogen-activated protein kinase (MAPK) and calcium/calmodulin-dependent protein kinase (CCaMK) are downstream signal of NO signal in the induction of oxidative tolerance Zhang et al., (2007); Ma et al., (2012). However, whether Mo induces the generation of NO by Mo-enzymes, particularly by NR, remains to be elucidate. Here, we hypothesized that Mo induces the generation of NO by Mo-enzymes, particularly by NR, and then mediates the antioxidant defense in winter wheat under drought stress. Testing of this hypothesis may facilitate a better understanding of the mechanism by which Mo improves drought stress tolerance in plants. 


\section{4-2 Through Inoculation with growth-promoting rhizobacteria (PGPR)}

The use of plant growth-promoting rhizobacteria (PGPR) is a useful practice for alleviating the harmful effects of drought in legumes Khan et al. (2019). Application of PGPR enhances plant growth under drought through direct and indirect mechanisms Khan et al. (2019). Niu et al. (2018), such as nitrogen fixation, phosphorus, and solubilization, production of siderophores, organic acids and plant growth-promoting compounds as well as important enzymes such as 1-aminocyclopropane-1carboxylic acid (ACC) deaminase, glucanase and chitinase Glick, et al .(2007), Hayat et al. (2010).

Plant growth-promoting rhizobacteria (PGPR) can regulate the main phytohormones such as gibberellins, auxins, Cytokinins, ABA and ethylene. Dimkpa et al (2009), which mitigates the harmful effects of drought to boost crop yield. Belimov, et al. (2009). Dimkpa et al. (2009) revealed that inoculation with rhizobacteria (RBs) enhanced root hair development and lateral root, helping to improve water and nutrient uptake. 1-aminocyclopropane-1-carboxylic acid (ACC) hydrolysis by RBs hinders ethylene production and improves root growth in plants Long, et al. (2008). Rhizobacteria (RBs) such as Bacillus, Burkholderia, and Arthrobacter also promote proline synthesis under drought stress (DS) Barka et al. (2006), Sziderics et al. (2007). In soybean and cowpea, proton efflux activities in root systems were significantly and positively affected by Azospirillum inoculation Bashan, and Alcaraz, (1992) Owing to ACC deaminase activity, RBs may convert ACC into a-ketobutyrate and ammonia, thereby shielding crop plants from harmful concentrations of ethylene Nadeem, et al. (2014) .Arbuscular mycorrhizal fungi (AMF) help to improve plant growth, yield, and uptake of water and nutrients under drought Augé (2001). AMF can improve soil structure and soil water retention ability through stabilization and formation of soil aggregates. AMF produces a glycoprotein (Glomalin), which plays a vital role in improving soil structure Smith et al. (2010). The extra radical mycelium of AMF can explore and extend a large soil volume, which assists in the better uptake of nutrients, and water from the soil. Thus, AMF greatly assist in regulating tissue water potential, an avoidance mechanism to alleviate the detrimental impacts of water deficit on plant growth and development Porcel, et al. (2004), Habibzadeh et al. (2014).

Additionally, inoculation with AMF can build up stress tolerance by increasing levels of osmoprotectants Porcel, et al. (2004), Habibzadeh et al. (2014), decreasing lipid peroxidation, and increasing antioxidant potential, Porcel et al. (2003), Sohrabi, et al. (2012), which ultimately boost final yield, Habibzadeh et al. (2014), Gaur and Adholeya (2002) observed improved plant growth and phosphate uptake in legume crops with AMF. A number of previous studies has witnessed that PGPR and AMF application have the ability to improve plant growth rate and crop yield under stress conditions by regulating hormonal and nutritional balances, solubilizing essential plant nutrients and producing plant growth regulators. Besides the positive effects of sole inoculation of PGPR and AMF, their combined application also improves drought resistance. Figueiredo et al. (2008) observed that application of Paenibacillus polymyxa and Rhizobium tropici on nodulation, $\mathrm{N}$ assimilation and growth in common bean under DS. Inoculation enhanced growth, nitrogen assimilation, and nodulation under water deficit as compared with the control.

\section{Conclusion}

Molybdenum nutrition is an essential component to healthy plant growth. Molybdate, which is the predominant form available to plants, is required at very low levels where it is known to participate in various redox reactions in plants as part of the pterin complex Moco. Moco is particularly involved in enzymes, which participate directly or indirectly with nitrogen metabolism. However, Moco is also uniquely involved in $\mathrm{ABA}$ synthesis where it has a significant effect on ABA levels in plant cells and consequently a role in water relations and transpiration rates through stomatal control and in stress related responses.

There is significant practices, which optimize molybdenum fertilization in crops and predominant nitrogen fertilization should be nitrate, particularly, in nitrogen fixing legumes. The mechanism that controlling molybdenum transport to nitrogen fixing bacteroids may be a unique control mechanism by which the plant can regulate the symbiosis indirectly through molybdenum availability to support nitrogenase activity.Drought stress is a major environmental stress that limits plant growth and crop production. Plants can developed various complicated adaptive mechanisms to cope particularly, under drought stress through a series of physiological and biochemical mechanisms processes, through physiological defenses such as antioxidant defense which plays a crucial role in the alleviation of 
damage caused by drought stress. Phytohormones and signal molecules are involved in the regulation of antioxidant defense, which destroy reactive oxygen species (ROS), and thus confers drought tolerance to plants. Molybdenum (Mo) has been extensively reported to facilitate the improvement of abiotic stress tolerance against salinity, low temperature and water stress in plants

\section{Reference}

Abdoli, M., M. Saeidi, S. Jalali-Honarmand, and M. Azhand. 2013. The effect of foliar application of indole-3-acetic acid (IAA) and roles of ear photosynthesis on grain yield production of two wheat cultivars (Triticum aestivum L.) under post anthesis water deficit. International Research Journal of Applied and Basic Sciences.4 (6): 1406-1413.

Adams, J.F., 1997. Yield response to molybdenum by field and horticultural crops. In: Gupta UC, ed. Molybdenum in agriculture. Cambridge University Press

Afridi, M.M.R.K., and E.J. Hewitt 1965. The inducible formation and stability of nitrate reductase in higher plants II Effects of environmental factors, antimetabolites and amino-acids on induction. J. Exp. Bot. 16:628-645.

Agarwala, S.C., and E.J. Hewitt, 1954. Molybdenum as a plant nutrient: IV. The interrelationships of molybdenum and nitrate supply in chlorophyll and ascorbic acid fractions in cauliflower plants grown in sand cultures. J. Hort. Sci. 29:291-300.

Agarwala, S.C., C.P. Sharma, S. Farooq, and C. Chatterjee, 1978. Effects of molybdenum deficiency on the growth and metabolism of corn plants raised in sand culture. Can. J. Bot. 56:1905-1909.

Allen, R.M., J.T. Roll, P. Rangaraj, V.K. Shah, G.P. Roberts, and P.W. Ludden, 1999. Incorporation of molybdenum into the iron-molybdenum cofactor of nitrogenase. J. Biol. Chem. 274:1586915874.

Anugroho, F., M. Kitou, F. Nagumo, K. Kinjo, and G. Jayasinghe 2010. Potential growth of hairy vetch as a winter legume cover crops in subtropical soil conditions. Soil Sci Plant Nutr., 56, 254-262.

Arkadiusz, Z., I.-N. Chantal, M. Vincent and L. Silke, 2019. The regulation of Moco biosynthesis and molybdoenzymes gene expression by molybdenum and iron in bacteria Metallomics, 11, 16021624.

Augé, R.M., 2001.Water relations, drought and vesicular-arbuscular mycorrhizal symbiosis. Mycorrhiza, 11, 3-42.

Babenko, O. N., G. Brychkova, M. Sagi, and Z. A. Alikulov, 2015. Molybdenum application enhances adaptation of crested wheatgrass to salinity stress. Acta Physiol. Plant. 37, 1-13. doi: 10.1007/s11738-014-1757-8

Banath, C.L., E.A.N. Greenwood, and J.F. Loneragan, 1996. Effects of Calcium Deficiency on Symbiotic Nitrogen Fixation. Plant Physiol. 41:760-763.

Bao-Ming, Ch., W. Sh.-X. L. Zhao- Hui, W. Gen-Xuan, S. Hai-Xing, and W. Xi-Na, 2004. Effects of nitrate supply on plant growth, nitrate accumulation, metabolic nitrate concentration and nitrate reductase activity

Barka, E.A., J. Nowak, and C. Cle, 2006. Enhancement of chilling resistance of inoculated grapevine plantlets with a plant growth-promoting rhizobacteria, burkholderia phytofirmans strain PsJN. Appl. Environ. Microbiol. , 72, 7246-7252.

Bashan, Y., and L. Alcaraz, 1992. Responses of soybean and cowpea root membranes to inoculation with Azospirillum brasilense. Symbiosis, 13, 217-228.

Belimov, A.A., I.C. Dodd, N. Hontzeas, J.C. Theobald, V.I. Safronova, and W.J. Davies, 2009 .Rhizosphere bacteria containing 1-aminocyclopropane-1-carboxylate deaminase increase yield of plants grown in drying soil via both local and systemic hormone signalling. New Phytol., 181, 413-423.

Brady, N.C., and R.R. Weil. 2008. Calcium, magnesium, and trace elements. In: V.R. Anthony, editor, The Nature and Properties of Soil. 14th ed. Pearson Prentice Hall, Upper Saddle River, NJ. P.639665 .

Broadley, M., P. Brown, I. Cakmak, Z. Rengel, and F. Zhao. 2012. Function of nutrients: micronutrients. In: P. Marschner, editor, Marschner's mineral nutrition of higher plants. 3rd ed. Academic Press, Waltham, MA. P.191-243. 
Brodrick, S.J., and K.E. Giller, 1991. Root nodules of Phaseolus: efficient scavengers of molybdenum for N2 fixation. J. Exp. Bot. 42:1339- 1343.

Brodrick, S.J. and K.E. Giller, 1991. Genotypic difference in molybdenum accumulation affects N; fixation in tropical Pharsalus vulgaris. J. Exp. Bot. 42: 1339-1343.

Brookins, D. G., 1987. Eh-pH Diagrams for geochemistry. New York: Springer-Verla

Bruning-Fann C.S., and J.B. Kaneene, 1993. The effects of nitrate, nitrite and N-nitroso compounds on human health: a review, Vet. Hum. Toxicol. 35 521-538.

Brychkova, G., Z. Zia, G. Yang, Z. Yesbergenova, Z. Zhang, O. Davydov, R. Fluhr, and M. Sagi. 2007. Sulfite oxidase protects plants against sulfur dioxide toxicity. The Plant Journal. 50(4):696-709.

Bryson, G.M., H.A Mills, D.N. Sasseville, J.B. Jones Jr., and A.V. Barker. 2014. Common name index to nutritional tables. Plant Analysis Handbook III: A guild to sampling, preparation analysis, interpretation and use of results of agronomic and horticultural crop plant tissue. Micro-Macro Publishing, Inc., Athens, GA. P.463.

Bussi, C.A., and L. Gojon, 1997. Passama, In situ nitrate reductase activity in Leaves of adult peach trees, J. Hortic. Sci. 72 347-353.

Caba, J.M., C. Lluch, and F. Ligero, 1995. Distribution of nitrate reductase activity in Vicia faba: effect of nitrate and plant genotype, Physiol. Plant 93 667-672.

Campo, R.J., U.B. Albino, and M. Hungria, 2000. Importance of molybdenum and cobalt to the biological nitrogen fixation. In Nitrogen Fixation: From Molecules to Crop Productivity, Eds. Pedrosa FO, Hungria M, Yates G, Newton WE, 597-598. Springer, Netherlands.

Cárdenas-Navarro R, S. Adamowicz, and P. Robin, 1999. Nitrate accumulationIn plants: a role for water, J. Exp. Bot. 50 613-624.

Chamizo-Ampudia, A., E. Sanz-Luque, Á. Llamas, F. Ocaña-Calahorro, V. Mariscal, A. Carreras, et al. 2016. A dual system formed by the ARC and NR molybdoenzymes mediates nitrite-dependent NO production in Chlamydomonas. Plant Cell Environ. 39, 2097-2107.

Chen, W. W., J. L. Yang, C. Qin, C. W. Jin, Mo, J. H. , T.Ye, et al. 2010. Nitric oxide acts downstream of auxin to trigger root ferric-chelate reductase activity in response to iron deficiency in Arabidopsis. Plant Physiol. 154, 810-819.

Chen, Z. H., Y. Wang, J. W. Wang, M. Babla, C. Zhao, C. García Mata, et al. 2016. Nitrate reductase mutation alters potassium nutrition as well as nitric oxide-mediated control of guard cell ion channels in Arabidopsis. New Phytol. 209, 1456-1469.

Datta, J.K., A. Kundu, S.D. Hossein, A. Banerjee, and N.K. Mondal. 2011. Studies on the impact of micronutrient (molybdenum) on germination, seedling growth and physiology of Bengal gram (Cicer arietium) under laboratory condition. Asian Journal of Crop Science 3(2): 55-67.

Delgado, M.J., E.J. Bedmar, and J.A. Downie, 1998. Genes involved in the formation and assembly of rhizobial cytochromes and their role in symbiotic nitro-gen fixation. Adv. Microb. Physiol. 40, 191-231.

Dimkpa, C., T. Weinand, and F. Asch, 2009. Plant-rhizobacteria interactions alleviate abiotic stress conditions .Plant Cell Environ. 32, 1682-1694.]

Drew E, and R. Ballard 2010. Improving N2 fixation from the plant down: compatibility of Trifolium subterraneum L. cultivars with soil rhizobia can influence symbiotic. performance. Plant Soil., 327, 261-277.

Elisabeth, P., V. Isabelle, D. Julien, C. Caroline, G. Clément, M. L. P. Marie-Christine, et al. 2014. Abscisic acid-induced nitric oxide and proline accumulation in independent pathways under water-deficit stress during seedling establishment in Medicago truncatula. J. Exp. Bot. 65, 21612170.

Ella, M., A. D. David and M. S. Penelope 2014. Iron: an essential micronutrient for the legumerhizobium symbiosis. Plant SC.Vol. (4) 1-15.

Engels, C., E. Kirkby, and P. White. 2012. Mineral Nutrition, Yield and Source-Sink Relationships. In: P. Marschner, editor, Marschner's mineral nutrition of higher plants. 3rd ed. Academic Press, Waltham, MA. P.85-133.

Faridul A., Y. K. Tae, Y.K. Song, S.A. Sadia, P.Prabhat, J.K. Pil and B. L. Yong 2015. Effect of molybdenum on nodulation, plant yield and nitrogen uptake in hairy vetch (Vicia villosa Roth), Soil Science and Plant Nutrition, 61:4, 664-675, 
Farook, M., A. Wahid, and K.H.M. Siddique 2012. Micronutrient application through seed treatments: a review. J. Soil Sci. Plant Nutr., 12(1), 125-142.

Ferrari, T.E, and O.C. Yoder, D 1973. Filner, Anaerobic nitrite production by plant cells and tissues: evidence for two nitrate pools, Plant Physiol. 51 423-431.

Figueiredo, V.B., A. Burity, C.R. Mart1, and C.P. Chanway, 2008. Alleviation of drought stress in the common bean (Phaseolus vulgaris L.) by co-inoculation with Paenibacillus polymyxa and Rhizobium tropici. Appl. Soil Ecol., 40, 182-188

Fortescue, J. A. C. 1992. Landscape geochemistry: retrospect and prospect 1990. Appl. Geochem. 7, 1 $-53$

Franco, A.A., and D.N. Munns, 1981. Response of Phaseolus vulgaris L to molybdenum under acid conditions. Soil Sci. Soc. Am. J. 45:1144-1148.

Gao, H., Y. Jia, S. Guo, G. Lv, T. Wang, and L. Juan. 2011. Exogenous calcium affects nitrogen metabolism in root-zone hypoxia-stressed muskmelon roots and enhances short-term hypoxia tolerance. Journal of Plant Physiology. 168 (11) 1217 - 1225.

Gastal, F., and G. Lemaire, 2002) N uptake and distribution in crops: an agronomical and Eco physiological perspective, J. Exp. Bot. 53 789-799.

Gaur, A., and A. Adholeya, 2002, Arbuscular-mycorrhizal inoculation of five tropical fodder crops and inoculum production in marginal soil amended with organic matter. Biol. Fertil. Soils 35, 214 218.

Glick, B.R., Z. Cheng, and J. Czarny, 2007.Promotion of plant growth by ACC deaminase-producing soil bacteria. Eur. J. Plant Pathal., 119, 329-339.

Gopal, R., and A.K. Shukla. 2017. Molybdenum stress modulates enzymes responsive to oxidative stress and affects seeds viability and vigor in chickpea. Commun. Soil. Sci. Plant Anal. 48(1):4350.

Graham, P., 1992. Stress tolerance in Rhizobium and Bradyrhizobium and nodulation under adverse soil conditions. Can. J. Microbiol. 38:475-484.

Gubler, W.D., 1982. Yellows of melons caused by molybdenum deficiency in acid soil. Plant Dis. 66(1):449-451.

Gungula, D., and Y. Garjila 2006. The effects of Molybdenum application on growth and yield of cowpea in Yola, Nigeria. Am- Eurasian J. Agric. Environ. Sci., 1, 96-101.

Gupta, G., B. Grund, and N. R. Radhika 1991. Photosynthesis and nitrogenase activity in soybean treated with sulphur dioxide and molybdenum. Plant Sci. 79 (2):157-161.

Gupta, U.C. 1997. Soil and Plant Factors Affecting Molybdenum Uptake by Plants. In: U.C. Gupta, editor, Molybdenum in agriculture. 1st ed. Cambridge University Press, New York, NY. P.7191.

Gurley, W.H., and J. Giddens 1969. Factors affecting uptake, yield response and carryover of molybdenum in soybean seed. Agron. J. 61:7-9.

Habibzadeh, Y., A.R. Evazi, and M. Abedi, 2014. Alleviation drought stress of mungbean (Vigna radiata L.) plants by using arbuscular mycorrhizal fungi. Int. J. Agric. Sci. Nat. Resour. 1, 1-6.

Haque, M.M., S.Y. Kim, P. Pramanik, G-Y Kim, and P.J. Kim 2013. Optimum application level of winter cover crop biomass as green manure under considering methane emission and rice productivity in paddy soil. Biol. Fertil. Soils, 49, 487-493.

Haque, I., 1987. Molybdenum in soils, plants, and its potential importance to livestock Nutrition, with special reference to sub-Saharan Africa. ILCA Bulletin 26:20-28.

Hara, Y., 2016. Improvement of seedling establishment under flood conditions by seed coating with molybdenum compounds for wheat and bareley. Plant Production Science 19(2):223-229.

Hayat, R., S. Ali, and U.Amara, 2010. Soil beneficial bacteria and their role in plant growth promotion: A review. Ann. Microbiol60, 579-598.

Hou, B.C., E.T. Wang, Y. Li, R.Z. Jia, W.F. Chen, C.X. Man, X.H. Sui, and W.X. Chen 2009. Rhizobial resource associated with epidemic legumes in Tibet. Microb. Ecol., 57, 69-81.

Ingle, J. 1966. The regulation of the activity of the enzymes involved in the assimilation of nitrate by higher plants. Biochem. J., 100, 577-588.

International Plant Nutrition Institute. 2017. Molybdenum. Nutri-Facts - North America. International Plant Nutrition Institute. http://www.ipni.net/publication/nutrifactsna. 
Ishiwata, H., T. Yamada, N. Yoshiike, M. Nishijima, A. Kawamoto, and Y. Uyama, 2002.Daily intake of food additives in Japan in five age groups estimated by the market basket method, Eur. Food Res. Technol. 215 367-374.

Ishizuka, J. 1982. Characteristics of molybdenum absorption and translocation in soybean plants. J. Soil Sci. Plant Nutr. 28:63-71.

Islam, M.R., T. Sultana, M.M. Joe, W. Yim, J-C Cho, and T. Sa 2013. Nitrogen-fixing bacteria with multiple plant growth-promoting activities enhance growth of tomato and red pepper.J. Basic Microbiol., 53, 1004-1015.

Jabbar, B.K.A., and H.M. Saud 2012. Effects of Molybdenum on biological nitrogen fixation by combination of Rhizobium and Azospirillium in soybean under drip irrigation system. Int.J. Life Sci. Bt. Pharm. Res., 1, 63-37.

Jones, J.B.J. 1998. Plant Nutrition Manual, 1st, CRC Press, Boca Raton, Florida. p. 149.

Jones, R.W., A.J. Abbott, E.J. Hewitt, D.M. James, and G.R. Best 1976. Nitrate reductase activity and growth in Paul's scarlet rose suspension cultures in relation to nitrogen source and molybdenum. Planta. 133:27-34.

Kaiser, B.N., K.L. Gridley, J.N. Brady, T. Phillips, and S.D. Tyerman. 2005. The role of molybdenum in agriculture plant production. Ann Botany. 96(5):745-754.

Kappler, U. and J.H. Enemark. 2015. Sulfite-oxidizing enzymes. J Biol Inorg Chem. 20(2):253-264.

Karimian, N. and F. R. Cox, 1978. Adsorption and extraction of molybdenum in relation to some chemical properties of soils. Soil Sci. Soc. Am. J. 42, 757-761.

Khan, N., A. Bano, and A. Babar, 2019.)Metabolic and physiological changes induced by plant growth regulators, plant growth promoting rhizobacteria, and their impact on drought tolerance in Cicer arietinum L. PLoS ONE, 13, e0213040.

Kisker, C., H. Schindlin, and D.C. Rees. 1997. Molybdenum-cofactor containing enzymes: Structure and mechanisms. Annual Review Biochemistry. 66:233-267.

Kubota, J., 1977. Molybdenum status of United States soils and plants. In Molybdenum in the Environment, Vol.2 (Chappell, W. R. and Peterson, 1<. K., eds.), New York: Marcel Dekker, pp. $555-581$.

Lambers, H., F.S. Chapin, and T.L. Pons, 1998. Plant Physiology and Ecology, 540. Springer, New York, NY.

Liu, P. 2002. Effects of the stress of molybdenum on plants and the interaction between molybdenum and other element. Agri. Environ. Protect. 21, 276-278

Lu, S., C. Zhuo, X. Wang, and Z. Guo, 2014. Nitrate reductase (NR)-dependent NO production mediates ABA- and H2O2 -induced antioxidant enzymes. Plant Physiol. Biochem. 74, 9-15.

Ludwig, W., and H.P. Klenk 2001. Overview: a Phylogenetic Backbone and Taxonomic Framework for Procaryotic Systematics. In Bergey's Manual of Systematic Bacteriology, pp. 49-65. Springer New York.

Ma, F., R. Lu, H. Liu, B. Shi, J. Zhang, M. Tan, et al. 2012. Nitric oxideactivated calcium/calmodulindependent protein kinase regulates the abscisic acid-induced antioxidant defence in maize. J. Exp. Bot. 63, 4835-4847.

Malla, R.M., B. Padmaja, S. Malathi, and R.L. Jalapathi 2007. Effects of micronutrients on growth and yield of pigeonpea. J. Semi-Arid Trop. Agric. Res., 5, 1-3.

Marcel, N., H. Hans-Michael, W. Mutsumi, H. Robert, S. MarkAurel and H. Rainer, 2018. Sulfite Reductase Co-Suppressio. In Tobacco Reveals Detoxification Mechanisms and Downstream Responses Comparable to Sulfate Starvation. Plant. SC. (9): 1-18.

Marschner, H., 2011. Marschner's Mineral Nutrition of Higher Plants, Academic press, London

Marschner, H., 1995. Mineral Nutrition of Higher Plants, Academic Press,London, 229-312.

Men, Z.H., and S.X. Li, 2005. Effects of molybdenum on nitrate metabolism of winter wheat. J. Plant Nutr. Fert., 11, 205-210.

Mendel, R.R., and R. Hänsch 2002. Molybdoenzymes and molybdenum cofactor in plants. J. Exp. Bot., 53, 1689-1698.

Mendel, R.R. 2011. Cell biology of molybdenum in plans. Plant Cell Reports. 30(10):1787- 1797.

Miller, A.J., and S.J. Smith, 1996. Nitrate transport and compartmentation in cereal root cells, JExp. Bot. $47843-854$. 
Nadeem, M.S., M. Ahmad, Z. Ahmad, A. Javaid, andM. Ashraf, 2014. The role of mycorrhizae and plant growth promoting rhizobacteria (PGPR) in improving crop productivity under stressful environments. Biotechnol. Adv., 32, 429-448.

Nautiyal, N., and C. Chatterjee, 2004. Molybdenum stress-induced changes in growth and yield of chickpea. J. Plant Nutr., 27(1), 173-181.

Nelson, D.N. 1984. Effect of nitrogen excess on quality of food and fiber. Nitrogen in Crop Production. ASA-CSSA-SSSA, Madison, WI. P.643-661.

Niu, X., L. Song, Y. Xiao, W. Ge, and D. Job, 2018. Drought-tolerant plant growth-promoting rhizobacteria associated with Foxtail Millet in a semi-arid agroecosystem and their potential in alleviating drought stress. Front. Microbiol. 8, 2580.

Oaks, A., 1994. Primary nitrogen assimilation in higher plants and its regulation Can. J. Bot. 72739 750.

Pollock, V.V., R.C. Conover, M.K. Johnson, and M.J. Barber 2002. Bacterial expression of the molybdenum domain of assimilatory nitrate reductase: production of both the functional molybdenum-containing domain and the nonfunctional tungsten analog. Arch. Biochem. Biophys., 403, 237-248.

Porcel, R., J.M. Barea, J.M. Ruiz-lozano, and J.M. Ruiz-lozano, ( 2003. Antioxidant activities in mycorrhizal soybean plants under drought stress and their possible relationship to the process of nodule senescence. New Phytol. 157, 135-143.

Porcel, R., and J.M. Ruiz-lozano, 2004. Arbuscular mycorrhizal influence on leaf water potential, solute accumulation, and oxidative stress in soybean plants subjected to drought stress. J. Exp. Bot., 55, $1743-1750$.

Pramanik, P., M.M. Haque, and P.J. Kim, 2013. Effect of nodule formation in roots of hairy vetch (Vicia villosa) on methane and nitrous oxide emissions during succeeding rice cultivation. Agric. Ecosyst. Environ., 178, 51-56.

Reddy K.J., L.C. Munn, and L. Wang, 1997. Chemistry and mineralogy of molybdenum in soils. In: Gupta U.C. (ed.): Molybdenum in Agriculture. Cambridge, Cambridge University Press, 4-22.

Randall, P.J., 1969. Change in nitrate and nitrate reductase levels on restoration of molybdenum-tomolybdenum-deficient plants. Aust. J. Agr. Res. 20:635-642.

Raven, P.H., R andF Evert, and S.E. Eichhorn 1999. Biology of Plants, 6th, W. H. Freeman and Company, Worth Publishers, New York, p. 686.

Reddy, K.J. and S. P. Gloss, 1993. Geochemical speciation as related to the mobility of F, Mo and Se in soil leachates. Appl. Geochem. (Suppl.) 2,159-163.

Reisenauer, H. M., A. A. Tabikh, and P. R. Stout, 1962. Molybdenum reactions with soils and the hydrous oxides of iron, aluminium and titanium. Soil Sci. Soc. Am. Proc. 26, 23-27.

Sang, J., M. Jiang, F. Lin, S. Xu, A. Zhang, and M. Tan, 2008a. Nitric oxide reduces hydrogen peroxide accumulation involved in water stress-induced subcellular anti-oxidant defense in maize plants. J. Integr. Plant Biol. 50, 231-243.

Sang, J., A. Zhang, F. Lin, M. Tan, and M. Jiang, 2008b. Cross-talk between calcium-calmodulin and nitric oxide in abscisic acid signaling in leaves of maize plants. Cell Res. 18, 577-588.

Sanz, L., P. Albertos, I. Mateos, I. Sánchez-Vicente, T. Lechón, M. Fernández- Marcos, et al. 2015. Nitric oxide (NO) and phytohormones crosstalk during early plant development. J. Exp. Bot. 66, $2857-2868$.

Schwarz, G., and R.R. Mendel. 2006. Molybdenum cofactor biosynthesis and molybdenum enzymes. Annu. Rev. Plant Biol. 57:623-647.

Sisson, V.A., T.W. Rufty, and R.E. Williamson, 1991. Nitrogen-use efficiency among Flue-cured tobacco genotypes, Crop Sci. 31 1615-1620.

Sivasankar, S, S. Rothstein, and A. Oaks, 1997. Regulation of the Accumulation and Reduction of nitrate by nitrogen and carbon metabolites in maize seedlings, Plant .Physiol. 114 583-589.

Smith, K.S., L.S. Balistrieri, S.M. Smith, and R.C. Severson. 1997. Distribution and mobility of molybdenum in terrestrial environment. In: U.C. Gupta, editor, Molybdenum in agriculture. 1st ed. Cambridge University Press, New York, NY. P.23- 46.

Smith, S.E., E. Facelli, S. Pope, and F.A. Smith, 2010. Plant performance in stressful environments: Interpreting new and established knowledge of the roles of arbuscular mycorrhizas. Plant Soil, $326,3-20$. 
Sohrabi, Y., G. Heidari, W. Weisany, K.G. Golezani, and K. Mohammadi, 2012. Some physiological responses of chickpea cultivars to arbuscular mycorrhiza under drought stress. Russ. J. Plant Physiol. 59, 708-716.

Solaiman, A.R.M. 1999. Effect of Bradyrhizobium japanicum inoculation and molybdenum on soybean. Bangladesh J. Bot., 28(2), 181-183.

Solomonson, L.P, and M.J. Barber, 1990. Assimilatory nitrate reductase: functional Properties and regulation, Annu. Rev. Plant Biol. 41 225-253.

Song, L., W. Ding, M. Zhao, B. Sun, and L. Zhang, 2006. Nitric oxide protects against oxidative stress under heat stress in the calluses from two ecotypes of reed. Plant Sci. 171, 449-458.

Spencer, D., and J.G. Wood 1954. The role of molybdenum in nitrate reduction in higher plants. Aust. J. Biol. Sci. 7:425-473.

Sun, X., C. Hu, Q. Tan, J. Liu, and H. Liu, 2009. Effects of molybdenum on expression of coldresponsive genes in abscisic acid (ABA)-dependent and ABA-independent pathways in winter wheat under low-temperature stress. Ann. Bot. 104, 345-356. doi: 10.1093/aob/mcp133

Sun, X., Q. Tan, Z. Nie, C. Hu, and Y. An, 2014. Differential expression of proteins in response to molybdenum deficiency in winter wheat leaves under low-temperature stress. Plant Mol. Biol. Rep. 32, 1057-1069.

Sziderics, A.H., F. Rasche, F. Trognitz, A. Sessitsch, and E. Wilhelm, 2007.Bacterial endophytes contribute to abiotic stress adaptation in pepper plants (Capsicum annuum L.. Can. J. Microbiol. 53, 1195-1202.

Tang, C., A.D. Robson, and M.J. Dilworth, 1990. A split-root experiment shows that iron is required for nodule initiation in Lupinus angustifolius L. New Phytol 115:61-67.

Thibaund, G.R., 2005. Molybdenum relationships in soils and plants. KwaZulu-Natal Department of Agriculture and Environmental Affairs, Cedara College, Private Bag X, 9059.

Tian, C.F., J.P.W. Young, E.T. Wang, S.M. Tamimi, and W.X. Chen 2010. Population mixing of Rhizobium leguminosarum bv. viciae nodulating Vicia faba: the role of recombination and lateral gene transfer. FEMS Microbiol. Ecol., 73, 563-576.

Van der Boon, J., J.W. Steenhuizen, and E.G. Steingröver, 1990. Growth andNitrate concentration of lettuce as affected by total nitrogen and chloride Concentration, NH4/NO3 ratio and temperature of the recirculating nutrient solution, J. Hortic. Sci. 65 309-321.

Vieira, R.F., E.J.B.N. Cardoso, C. Vieira, S.T.A. Cassini 1998. Foliar application of molybdenum in common beans. I. Nitrogenase and reductase activities in a soil of high fertility.J. Plant Nutr., 21(1), 169-180.

Wang, Z.-H., Z.-Q. Zong, S.-X. Li, B.-M. Chen, 2002.Nitrate accumulation in vegetables and its residual in vegetable fields, Environ. Sci. 23 79-83.

Westermann, D.T. 2005. Nutritional requirements of potatoes. Am. J. Potato Res. 82:301-307.

Williams, R.J.P., and J.J.R. Frausto da Silva 2002. The involvement of molybdenum in life. Biochem. Biophys. Res. Comm., 293-299.

Wu, S., C. Hu, Q. Tan, L. Lu, K. Shi, Z. Yong, et al. 2015. Drought stress tolerance mediated by zincinduced antioxidative defense and osmotic adjustment in cotton (Gossypium hirsutum. Acta Physiol. Plant. 37, 167.

Wu, S., C. Hu, Q. Tan, Z. Nie, and X. Sun, 2014. Effects of molybdenum on water utilization, antioxidative defense system and osmotic-adjustment ability in winter wheat (Triticum aestivum) under drought stress. Plant Physiol. Biochem. 83, 365-374.

Yan, A., and Z. Chen. 2016. The pivotal role of abscisic acid signaling during transition from seed maturation to germination. Plant Cell Rep. 1-15.

Zhang, A., M. Jiang, J. Zhang, H. Ding, S. Xu, X. Hu, et al. 2007. Nitric oxide induced by hydrogen peroxide mediates abscisic acid-induced activation of the nitogen activated protein kinase cascade involved in antioxidant defense in maize leaves. New Phytol. 175, 36-50.

Zhang, A., J. Zhang, J. Zhang, N. Ye, H. Zhang, M. Tan, et al. 2011. Nitric oxide mediates brassinosteroid-induced ABA biosynthesis involved in oxidative stress tolerance in maize leaves. Plant Cell Physiol. 52, 181-192.

Zhang, M., C. Hu, X. Zhao, Q. Tan, X. Sun, A. Cao, et al. 2012. Molybdenum improves antioxidant and osmotic-adjustment ability against salt stress in Chinese cabbage (Brassica campestris L. ssp. Pekinensis. Plant Soil 355, 375-383. 